\title{
Seasonal variability of the Caspian Sea three-dimensional circulation, sea level and air-sea interaction
}

\author{
R. A. Ibrayev ${ }^{1,2}$, E. Özsoy ${ }^{3}$, C. Schrum ${ }^{4}$, and H. ̇̇. Sur ${ }^{5}$ \\ ${ }^{1}$ Institute of Numerical Mathematics, Russian Academy of Sciences, Moscow, Russia \\ ${ }^{2}$ P. P. Shirshov Institute of Oceanology, Russian Academy of Sciences, Moscow, Russia \\ ${ }^{3}$ Institute of Marine Sciences, Middle East Technical University, Erdemli-Mersin, Turkey \\ ${ }^{4}$ Geophysical Institute, The University of Bergen, Bergen, Norway \\ ${ }^{5}$ Institute of Marine Sciences and Operation, Istanbul University, Istanbul, Turkey
}

Received: 10 June 2009 - Published in Ocean Sci. Discuss.: 1 September 2009

Revised: 21 January 2010 - Accepted: 28 January 2010 - Published: 3 March 2010

\begin{abstract}
A three-dimensional primitive equation model including sea ice thermodynamics and air-sea interaction is used to study seasonal circulation and water mass variability in the Caspian Sea under the influence of realistic mass, momentum and heat fluxes. River discharges, precipitation, radiation and wind stress are seasonally specified in the model, based on available data sets. The evaporation rate, sensible and latent heat fluxes at the sea surface are computed interactively through an atmospheric boundary layer sub-model, using the ECMWF-ERA15 re-analysis atmospheric data and model generated sea surface temperature. The model successfully simulates sea-level changes and baroclinic circulation/mixing features with forcing specified for a selected year. The results suggest that the seasonal cycle of wind stress is crucial in producing basin circulation. Seasonal cycle of sea surface currents presents three types: cyclonic gyres in December-January; Eckman south-, south-westward drift in February-July embedded by western and eastern southward coastal currents and transition type in August-November. Western and eastern northward subsurface coastal currents being a result of coastal local dynamics at the same time play an important role in meridional redistribution of water masses. An important part of the work is the simulation of sea surface topography, yielding verifiable results in terms of sea level. The model successfully reproduces sea level variability for four coastal points, where the observed data are available. Analyses of heat and water budgets confirm climatologic estimates of heat and mois-
\end{abstract}

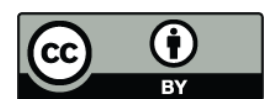

Correspondence to: R. A. Ibrayev (ibrayev@inm.ras.ru) ture fluxes at the sea surface. Experiments performed with variations in external forcing suggest a sensitive response of the circulation and the water budget to atmospheric and river forcing.

\section{Introduction}

The Caspian Sea is the largest totally enclosed water body on Earth, constituting $44 \%$ of the global volume of lacustrine waters. Compared to other semi-enclosed and enclosed seas of the world, little is known of the Caspian Sea variability. The most urgent, yet unresolved questions relating to the Caspian Sea are: what is the three-dimensional general circulation of the sea and how does it affect transport of pollutants? How is this circulation created? Through which climatic and dynamic mechanisms is the sea level variability controlled? The phenomenological evidence is too ambiguous or insufficient to give satisfactory answers to these questions.

The Caspian Sea has an elongated geometry $(1000 \mathrm{~km}$ in length and $200-300 \mathrm{~km}$ in width), where the Northern, Middle and Southern Caspian Basins (respectively the NCB, MCB and SCB) constitute the main geographic divisions, as illustrated by the model bottom topography in Fig. 3. The shallow NCB has maximum depth of about $20 \mathrm{~m}$, while the MCB and SCB have deep troughs with maximum depths of $788 \mathrm{~m}$ and $1025 \mathrm{~m}$, respectively. Shelf areas with depth less than $100 \mathrm{~m}$, mainly along the northern and eastern coasts, account for $62 \%$ of the total area. The underwater extension of the Apsheron peninsula forms a sill separating the MCB and the SCB, with maximum depth of about $180 \mathrm{~m}$. The SCB

Published by Copernicus Publications on behalf of the European Geosciences Union. 
contains two thirds and the NCB makes up 1\% of the total volume of water (Kosarev and Yablonskaya, 1994).

The sea surface temperature (SST) in the NCB ranges from below zero under frozen ice in winter to $25-26^{\circ} \mathrm{C}$ in summer, while more moderate variability occurs in the SCB, changing from $7-10^{\circ} \mathrm{C}$ in winter to $25-29^{\circ} \mathrm{C}$ in summer. The seasonal thermocline occurs at a depth of 20-30 m during the warm season. Seasonal changes in thermal stratification typically reach a depth of $100 \mathrm{~m}$ in the SCB and to $200 \mathrm{~m}$ in the $\mathrm{MCB}$, while convection is known to reach the bottom in parts of the MCB during severe winters (Kosarev, 1975).

The Caspian Sea has low salinity. In deep water areas, salinity varies little with depth (12.80-13.08 psu), and the density stratification largely depends on temperature changes (Terziev et al., 1992). Sharp gradients of salinity occur near the mouths of rivers such as the Volga, where it changes from 2 to 10 , typically at a distance of about $20-100 \mathrm{~km}$ from the coast.

The elongated geometry and strong topography of the basin, acted upon by variable wind forcing and baroclinic effects result in spatially and temporally variable currents in the Caspian Sea. Despite strong variability of the sea currents, the general circulation has been described to be cyclonic, based on the results of investigations carried out from the end of 19th century till 1950's, either using indirect estimates of currents (floats, bottles or the dynamic method), or simple hydrodynamic interpretations (Bondarenko, 1993; Terziev et al., 1992). Especially standing out among these were the six instrumental surveys along the western coast of the MCB, carried out in the years 1935-1937 (Stockman, 1938; Baidin and Kosarev, 1986), showing predominantly southward currents along the western coast of the MCB, modified by winddriven currents close to the surface. A synthesis of these results has led to the current scheme of Lednev (1943) (Fig. 1).

Since the 1950's, regular oceanographic observations and current measurements in coastal areas shallower than $100 \mathrm{~m}$ have confirmed some circulation features illustrated in Fig. 1. Accordingly, the southward currents have been well established along the western coast of MCB; while the northward currents indicated along the eastern coast contradict with summertime observations of surface southward currents in the same region. The cyclonic general circulation of Fig. 1 is partially supported by observed northward currents below of a surface layer (7-8 m depth) of southward drift currents along the eastern coast. It appears that the southward surface currents along the eastern coast are driven by winds with a prevailing southward component in the eastern halves of the MCB and SCB from spring till autumn. The circulation indicated in the shallow NCB appears to be almost totally controlled by local winds (Bondarenko, 1993; Terziev et al., 1992; Kosarev and Yablonskaya, 1994).

The Caspian Sea differs from other inland seas, e.g. the Mediterranean and the Black Seas, with respect to an extensive region of upwelling along the eastern coast of the MCB in summer, expressed by a well-defined pattern of cold wa-

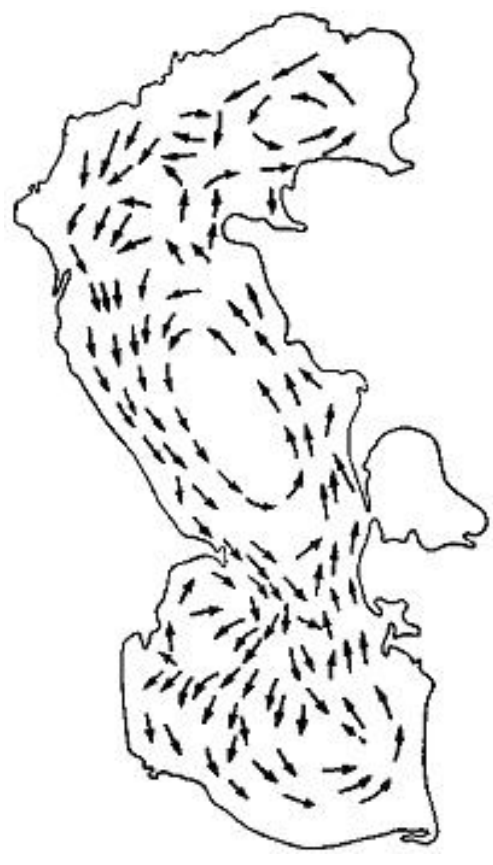

Fig. 1. Scheme of the Caspian Sea sea currents (Lednev, 1943).

ter detected in satellite images (Sur et al., 1998) and also revealed by climatological temperature fields in the warm season (Kosarev and Tuzhilkin, 1995). Although winter upwelling is also possible under favourable winds, detection by satellite remote sensing becomes more difficult in the cold season, as a result of smaller temperature contrasts with the surrounding waters.

The water budget of the landlocked Caspian Sea is extremely sensitive to climatic variability in the surrounding areas. With a large catchment area extending towards the Urals and Caucasia, river runoff dominates the water budget (with an annual average of $\sim 3 \times 10^{11} \mathrm{~m}^{3} \mathrm{yr}^{-1}$ and a range of 2.0 $4.5 \times 10^{11} \mathrm{~m}^{3} \mathrm{yr}^{-1}$ during the period $1900-1990$, Terziev et al. (1992). Annual precipitation is about one third of runoff, while evaporation approximately is equal to the sum of precipitation and runoff. Runoff and evaporation each correspond to about $1 \mathrm{~m} / \mathrm{yr}$ of sea level change. The main reason for sea level changes, observed throughout history, is the climate variability affecting the Caspian Sea basin. Anthropogenic factors such as the construction of water reservoirs on the Volga river after 1940-ies have caused changes in the water budget. As estimated by Rodionov (1994) the mean rate of decline of the sea level in 1941-1977 is $3 \mathrm{~cm} / \mathrm{yr}$. If anthropogenic activities are corrected for and only natural factors (i.e. runoff without water withdrawal) are considered, a sea level rise of about $1.5 \mathrm{~cm} / \mathrm{yr}$ is estimated. Part of the water budget of the Sea in addition to the main terms (river runoff + precipitation - evaporation) is the exchange with the Kara-Bogaz-Gol, a small interconnected basin on the arid eastern coast, which acts as an important sink in 
the water balance. Annual discharge in the 1900-1990 period has been about $10 \mathrm{~km}^{3} \mathrm{yr}^{-1}$, corresponding to a $3 \mathrm{~cm} / \mathrm{yr}$ change in Caspian Sea level. Normally, the Caspian Sea level controls discharge into the Kara-Bogaz-Gol. However, as a remedy for strong sea level decline in late 70-ies, the outflow to Kara-Bogaz-Gol Bay has been blocked by a dam constructed in early 1980-ies. During 1930-1977, the sea level decreased to $-29 \mathrm{~m}$ relative to the mean sea level of the global ocean, from the earlier value of about $-26 \mathrm{~m}$ lasting from the beginning of the century till the 1930's. From 1977 onwards, it increased once again to reach the pre-1930's levels. Rapid sea level change occurred in both of these periods, as indicated in Fig. 2 for 1977-1995. Superposed on these inter-decadal changes, the sea level displays a clear seasonal cycle in Fig. 2, as a function of the net water budget (river inflow + rainfall - evaporation). The sea level reaches its lowest seasonal value in winter and increases in the MayJuly period, following the spring floods. The climatological mean seasonal range of sea level is about $30 \mathrm{~cm}$ (Baidin et al., 1986).

Earlier models of sea level variability (e.g. Rodionov, 1994) generally considered the problem from a stochastic point of view. While stochastic models had a certain level of success, a more fundamental understanding can only be based on controls by hydrological as well as oceanic processes. The total water fluxes across the sea surface and river mouths determine the mean sea level in an enclosed water body such as the Caspian Sea. Surface fluxes of momentum, water and heat are coupled together, and can strongly be modified by the surface temperature and circulation of the sea. On the other hand, these fluxes are the basic elements of the regional hydrological cycle coupled to the global climate. New findings suggest linkages of the Caspian Sea level to ENSO/El Niño via the Indian Monsoon (Bengtsson, 1998), further supported by predictions of multi-decadal fluctuations and increased river discharges associated with global warming scenarios (Arpe and Roeckner, 1999).

In the past, modelling of the Caspian Sea circulation has been rather limited in scope, relying mostly on diagnostic models. A baroclinic diagnostic model (Sarkisyan et al., 1976) has shown the importance of wind stress and summer-time thermal stratification in establishing the circulation. The space-time variability of the summer circulation in response to prevailing north-west and south-east winds was studied by Badalov and Rzheplinski (1989), who combined results from non-stationary models of the NCB and of the upper ocean with a diagnostic model of the deep waters. Akhverdiev and Demin (1989), Kosarev and Yablonskaya (1994), and Terziev et al. (1992) presented a number of diagnostic studies of climatic and synoptic situations. The dynamically adjusted climatic seasonal circulation investigated by Trukhchev, Kosarev, Ivanova, and Tuzhilkin (1995) and Tuzhilkin, Kosarev, Trukhchev, and Ivanova (1997) showed persistent cyclonic and anticyclonic vortices respectively in the north-west and the south-east sec-

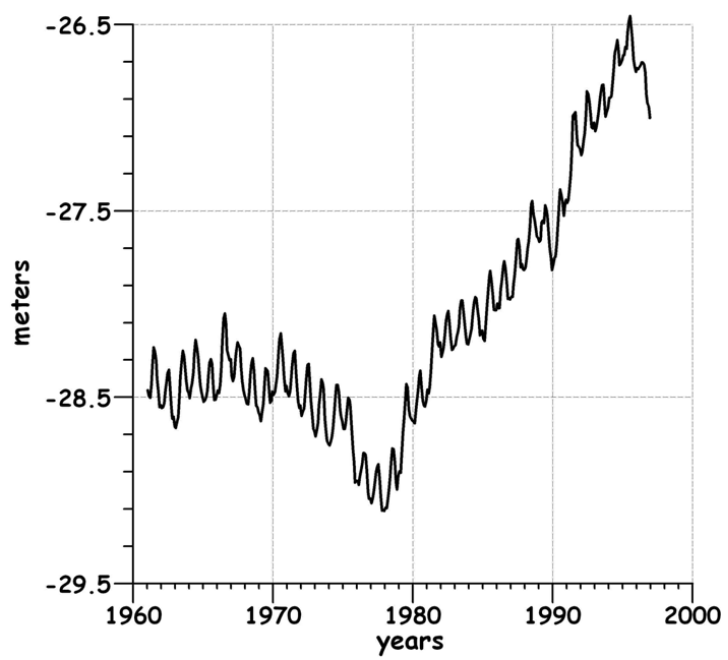

Fig. 2. Caspian mean sea level during the 1961-1996 period.

tors of the MCB, and anticyclonic vortices in the north-west and the south-east of the SCB, to be the main elements of the circulation. The success of these diagnostic studies was limited by the spatial resolution and quality of the available hydrological data.

Considering the general lack of understanding of the Caspian Sea circulation and sea level variability, we aim (i) to develop a 3-D circulation model with variable water mass in the basin, including air-sea interaction and sea ice thermodynamics sub-models; (ii) to study the seasonal variability of the circulation and sea level, and in particular the processes controlling the sea level.

A description of the model and its forcing is given in Sects. 2 and 3. In Sect. 4 we analyse the seasonal circulation, water budget and the resulting sea level variability in correspondence with heat and evaporation fluxes at the airsea interface. In Sect. 5 we consider the sensitivity of the model results to external forcing and model parameters.

\section{Model description}

\subsection{General remarks}

The enclosed geometry and size of the Caspian Sea are advantageous for numerical modelling. On the other hand, greater constraints are imposed in formulation of boundary fluxes in enclosed basin as compared to semi-enclosed or open seas, as improper accounting of mass or buoyancy fluxes could lead to unrealistic trends of total stored mass, heat and salt in the model.

Modeling of the seasonal cycle implies integration of the model equations for several years subject to periodic annual atmospheric and river forcing, based on the assumption that the solution does not have a long term trend. If a climatological steady state exists, this assumption is valid. For 
the Caspian Sea it is rather difficult to find a 30 -year period with stable sea level, especially after the 1950-es, when corresponding atmospheric observations have become more abundant. It should be noted that the sea level response is an integrated function of the forcing and internal dynamics. Use of forcing with trend in water balance will mean that the yearly net sea level change will not be zero. Consequently, the simulation with an inaccurate forcing (possibly with an unrealistic trend) for about 10 years (otherwise sufficient for getting a quasi-periodic solution for the relatively small Caspian Sea) will result in a solution that diverges from reality. The means to escape this are either i) to artificially balance the water budget of the basin; or ii) to adjust solution so as to have zero mean sea level at the end of every model year. Both of these methods have drawbacks. We have therefore chosen to force the model with data corresponding to a period with nearly balanced water budget.

One of the choices would have been to force the system with climatic atmospheric forcing. This would have the above stated disadvantage of having an unrealistic trend in it, reflected in the observed evolution in sea level after the 1950es. The other choice, which has been adopted, is to simulate a single year in which the net sea level change between the first and the last day is minimal. Our analyses, based on a literature search and discussion with experts showed 1982 to be a candidate satisfying the above criteria within the 1979-1993 period, corresponding to the ERA15 atmospheric re-analysis data that has been used (see Sect. 3). 1982 had been a balanced year with respect to water budget while the Volga river run-off $\left(222.3 \mathrm{~km}^{3} \mathrm{yr}^{-1}\right)$, was at a medium range that is still larger than 11 other years in the 37-year period from 1961 till 1997. Considering the general lack of understanding of the Caspian Sea circulation and sea level variability pointed in Introduction section, we directed our attention to a single year with balanced water budget so as to investigate dynamical linkages of the system, and to establish a starting point for future investigations. The one-year simulation obviously will not answer all the questions with respect to the multi-decadal climatic oscillations of the system, especially at the present level of availability of observational data, but we hope further studies will be made of the inter-annual variability aspects. One of the questions in this respect is the role of the changing volume and surface area of the Caspian Sea, modifying its response characteristics as a function of sea-level. The change in sea surface area is a factor in stabilizing sea level variations on inter-annual timescales. For example, a $2 \mathrm{~m}$ rise in sea level would result in $10 \%$ increase in sea surface area, giving rise to increased evaporation, which would then have a feedback on sea level response. In continuing studies of inter-annual variability aspects, we plan to use flooding and drying algorithms to answer these questions. On seasonal timescales the changes in water masses normally result in sea level variations of about $0.25 \mathrm{~m}$, corresponding to about $1.3 \%$ change in the sea surface area, neglected in the present study.
Sea level change is a direct result of water balance, which depends on the quality of estimation of the river inflows and air-sea water fluxes. River inflows and precipitation, as remotely defined functions, are prescribed in the model, while evaporation depends on local air-sea interaction, i.e. atmospheric parameters (air temperature, humidity, wind speed) near the sea surface and SST. The air-sea interaction module used for computing fluxes is therefore an essential part of the model because systematic errors in mass flux specified otherwise could rapidly contaminate the SST and lead to greatly differing estimates of sea level.

An essential for the model formulation is capability to simulate variability of total water mass in the basin. We use the kinematic equation at the sea surface, which make it possible to introduce time-varying thickness of the upper layer in correspondence with the continuity equation.

An important issue concerning the formulation of boundary conditions arise from the fact that fresh water income and outflow plays an important role in the sea dynamics. Thus the estimates show that the hydrological turnover time for the Sea is of the order of 200 years and for the shallow NCB of the order of 1 year. As was discussed by Beron-Vera, Ochao and Ripa (1999), use of ad hoc surface boundary conditions for salt balance, such as salt relaxation or "virtual" salt flux conditions are unphysical in nature because they create or destroy salt mass. The correct boundary conditions should include the fact that the vast majority of the salt particles remain in the sea during evaporation, and that the precipitated water is essentially pure freshwater. In formulation of boundary conditions for salt, heat and momentum fluxes we follow the approach of Beron-Vera et al. (1999), and of Roulett and Madec (2000) and add to the usual formulation of air-sea fluxes the terms responsible for freshwater influence.

In the study we use the free-surface, primitive equation, z-level numerical Model for Enclosed Sea Hydrodynamics (MESH), described by Ibrayev (2001), employing Boussinesq and hydrostatic approximations. Formulation of freesurface condition in the model allows propagation of surface gravity waves and mean sea surface elevation changes in response to non-zero water balance.

\subsection{Governing equations}

The basic equations of the model in spherical coordinates $(\lambda$ - longitude, $\varphi$ - latitude, $z$-depth) are the following:

$$
\begin{aligned}
& u_{t}+(\boldsymbol{v} \cdot \nabla) u+w u_{z}-f v+a^{-1} t g \varphi u^{2}=-\left(\rho_{0} a \cos \varphi\right)^{-1} p_{\lambda} \\
& +\left(K_{m} u_{z}\right)_{z}+D_{u} \\
& v_{t}+(\boldsymbol{v} \cdot \nabla) v+w v_{z}+f u+a^{-1} \operatorname{tg} \varphi u v=-\left(\rho_{0} a\right)^{-1} p_{\varphi} \\
& +\left(K_{m} v_{z}\right)_{z}+D_{v} \\
& p_{z}=\rho g \\
& \nabla \boldsymbol{v}+w_{z}=0
\end{aligned}
$$


$T_{t}+(\boldsymbol{v} \cdot \nabla) T+w T_{z}=\left(K_{h} T_{z}\right)_{z}+D_{T}+\left(\rho_{o} c_{p}\right)^{-1} I_{z} \cdot(1-A)$

$S_{t}+(\boldsymbol{v} \cdot \nabla) S+w S_{z}=\left(K_{h} S_{z}\right)_{z}+D_{S}$

$\rho=\rho(T, S)$

where $\boldsymbol{v}=(u, v)$ is the horizontal velocity vector; $w$ the vertical velocity; $T, S, \rho$ the temperature, salinity and density of sea water; $\rho_{o}$ - mean density; $f=2 \Omega \sin \varphi$ the Coriolis parameter, $\Omega$ representing the angular velocity of Earth's rotation; $\nabla \eta=\left((a \cos \varphi)^{-1} \eta_{\lambda}, a^{-1} \eta_{\varphi}\right)$ the two dimensional gradient operator; $K_{m}, K_{h}$ the vertical turbulent viscosity and diffusion coefficients for momentum and scalars; $D_{u}, D_{v}, D_{T}, D_{S}$ the horizontal turbulent viscosity and diffusion terms for momentum, heat and salinity; $a$ the Earth's radius; $c_{p}$ the specific heat of sea water; $I$ the incoming solar irradiance; $A$ - sea ice compactness. The UNESCO equation of state for sea water (UNESCO, 1976) is used in Eq. (7).

For stable stratification, we use Richardson number dependent parameterization of the vertical mixing coefficients proposed by Munk and Anderson (1948):

$K_{m}=a_{m 0}(1+\alpha R i)^{-n}+a_{m b}$

$K_{h}=a_{h 0}(1+\alpha R i)^{-n}+a_{h b}$

where $a_{m 0}, a_{m b}, a_{h 0}, a_{h b}, \alpha, n$ are empirical constants, and $R i$ is the Richardson number defined as $R i=g \rho_{z} \rho_{0}^{-1}\left[\left(u_{z}\right)^{2}+\left(v_{z}\right)^{2}\right]^{-1}$. In the case of unstable stratification, water is mixed instantaneously with conservation of total heat and salt in mixed volumes of water.

Horizontal mixing terms $\left(D_{u}, D_{v}, D_{T}, D_{S}\right)$ expressed in the form $D_{\eta}=(a \cos \varphi)^{-1}\left[\left(A_{\eta} \eta_{\lambda} a^{-1} \cos ^{-1} \varphi\right)_{\lambda}\right.$ $\left.+\left(A_{\eta} \eta_{\varphi} a^{-1} \cos \varphi\right)_{\varphi}\right]$, where $\eta$ stands for either one of the velocity components $u, v$, temperature or salinity $T, S$, and $A_{\eta}$ stands for the horizontal viscosity $\left(A_{m}\right)$ or diffusion $\left(A_{h}\right)$ coefficients, depending on which term is represented.

\subsection{Boundary conditions}

Sea surface evolution equation taking into account water fluxes is (Kamenkovich, 1973; Ibrayev, 2001):

$w+\zeta_{t}=\rho_{f}^{-1} W$

with $W=P+M-E$, where $\zeta(\lambda, \varphi, t)$ is the sea surface elevation; $\rho_{f}$ - density of fresh water; $W$ - water flux; $P$ precipitation; $M$ - water flux due to ice melting/freezing; $E$ - the rate of evaporation.

Upper boundary conditions are specified at the sea surface $z=\zeta(\lambda, \varphi, t)$ :

$-K_{m}\left(u_{z}, v_{z}\right)+(u, v) \cdot \rho_{f}^{-1} W=\rho_{o}^{-1}(1-A)\left(\tau^{\lambda}, \tau^{\varphi}\right)$

$p=p_{a}$

$-c_{p} K_{h} T_{z}+c_{p} T \rho_{f}^{-1} W=\rho_{o}^{-1}\left[Q_{h}^{\mathrm{aw}}(1-A)+Q_{h}^{\mathrm{iw}} A\right]$
$-K_{h} S_{z}+S \rho_{f}^{-1} W=\rho_{o}^{-1} S^{\mathrm{iw}} M A$

where $\left(\tau^{\lambda}, \tau^{\varphi}\right)$ are the wind stress components; $p_{a}$ - atmospheric pressure; $Q_{h}^{\mathrm{aw}}, Q_{h}^{\mathrm{iw}}$ - air-water and ice-water heat fluxes; $S^{\text {iw }} M$ the rate of salt flux in the sea due to ice melting/freezing. The second terms of the left side of Eq. (11), Eq. (13), Eq. (14) describe change of salt, heat and momentum content of the surface waters due to fresh water fluxes.

At the sea bottom, $z=H(\lambda, \varphi)$, the corresponding boundary conditions are:

$w=u(a \cos \varphi)^{-1} H_{\lambda}+v a^{-1} H_{\varphi}$

$\rho_{o} K_{m}\left(u_{z}, v_{z}\right)=\left(\tau_{B}^{\lambda}, \tau_{B}^{\varphi}\right)$

$K_{h}\left(T_{z}, S_{z}\right)=0$,

where $\left(\tau_{B}^{\lambda}, \tau_{B}^{\varphi}\right)$ are the bottom stress components.

At lateral walls, the free slip boundary condition and zero heat and salt fluxes are imposed:

$\boldsymbol{v}_{n}=0, \frac{\partial \boldsymbol{v}_{\tau}}{\partial \boldsymbol{n}}=0$

$A_{h}\left(\frac{\partial T}{\partial \boldsymbol{n}}, \frac{\partial S}{\partial \boldsymbol{n}}\right)=0$

where $\boldsymbol{n}$ and $\boldsymbol{\tau}$ represent respectively the normal and tangential directions to the surface. The general formulation of the numerical model has also inflow and outflow open boundaries. At inflow boundaries horizontal velocity components as well as temperature and salinity are prescribed:

$(u, v, T, S)=\left(u^{\text {in }}, v^{\text {in }}, T^{\text {in }}, S^{\text {in }}\right)$

while at outflow boundaries only the horizontal velocity components are prescribed

$(u, v)=\left(u^{\text {out }}, v^{\text {out }}\right)$

and the scalars are allowed to advect out of the region with this velocity.

\subsection{Air-sea interaction and sea ice models}

The heat fluxes at the sea and ice upper boundaries are the sum of solar surface and long-wave backward radiations, sensible and latent heat fluxes at the sea surface. The momentum, sensible heat and evaporation fluxes are calculated through the air-sea interaction sub-model based on the Monin-Obukhov similarity theory. The bulk transfer coefficients depend on universal functions relevant to the given stability conditions of the atmospheric boundary layer. Inputs for the air-sea interaction sub-model are the air and dew point temperature at $2 \mathrm{~m}$ above the sea surface, wind speed at $10 \mathrm{~m}$ and the sea surface temperature. The method of iterative flux calculations is based on the approach of Launiainen and Vihma (1990).

Whenever thermal conditions are favourable to form ice, air-sea fluxes are modified to account for the effects of sea-ice, based on the thermodynamic sea-ice sub-model of Schrum and Backhaus (1999). 


\subsection{Penetration of solar radiation}

Although more than half of the incoming solar radiation that enters the ocean in the long wave spectral band is absorbed within the top half meter, the remaining short wave fraction, as it penetrates through the surface waters, modifies SST by absorption, which in turn affects the rate of evaporation, leading to an impact on the water balance of the sea. The subsurface profile for solar radiation is computed using the twoband approximation of Paulson and Simpson (1977):

$I(z)=Q_{s}\left[R \cdot \exp \left(-z / \zeta_{1}\right)+(1-R) \cdot \exp \left(-z / \zeta_{2}\right)\right]$

where $Q_{s}$ is the downward flux of incoming solar radiation; $R$ is an empirical constant; $\zeta_{1}, \zeta_{2}$ are respectively the attenuation lengths for long wave and short wave spectral bands of solar radiation. For a one-dimensional model, Martin (1985) has found his model simulations sensitive to the optical properties of the given type of seawater. For enclosed and semienclosed seas, Timofeev (1983) adopts a value of $R=0.53$ for the empirical constant. Attenuation lengths for long wave radiation are typically small (we use $\zeta_{1}=0.033 \mathrm{~m}$, as proposed by Timofeev, 1983), so that total absorption occurs in the first model layer. The attenuation length for short wave band of solar radiation strongly depends on turbidity and differs between coastal and offshore regions. For the Caspian Sea its value is estimated to be about $10-15 \mathrm{~m}$ in the central parts of the MCB and SCB, and about 1-5 $\mathrm{m}$ in the NCB (Terziev et al., 1992). We parameterized the short wave attenuation length as depending on local depth, $\zeta_{2}=15 \mathrm{~m}$, for $H>100 \mathrm{~m}$ and $\zeta_{2}=(15 \mathrm{~m} / 100 \mathrm{~m}) H$, for $H<100 \mathrm{~m}$, where $H$ is the depth of the bottom.

\subsection{The model resolution}

The grid resolution of the model is $(1 / 12)^{\circ}$ in latitude and $(1 / 9)^{\circ}$ in longitude, which gives a grid size of about $9.3 \mathrm{~km}$. There are 22 vertical model levels defined at depths of 1,3 , $7,11,15,19,25,35,50,75,100,125,150,200,250,300$, $400,500,600,700,800,900 \mathrm{~m}$.

The maximum depth in the model is $950 \mathrm{~m}$, and a minimum depth of $5 \mathrm{~m}$ occurs in the shelf region of the NCB. The bottom topography and coastline correspond to the conditions during 1940-1955, when the mean sea level was $28 \mathrm{~m}$ below the global ocean level. The model bottom topography in Fig. 3 realistically represents the flat NCB shelf, the steep topographic slopes of the SCB and of the western part of the $\mathrm{MCB}$, as well as a number of islands.

\subsection{Initial conditions}

The model is initialized from a state of rest corresponding to the climatologic state of the sea in November (Fig. 4) in order to overcome the lack of temperature and salinity data in winter in regions under ice cover.

The values of vertical and lateral mixing coefficients were selected to have the following values: $\left(a_{m 0}\right.$,

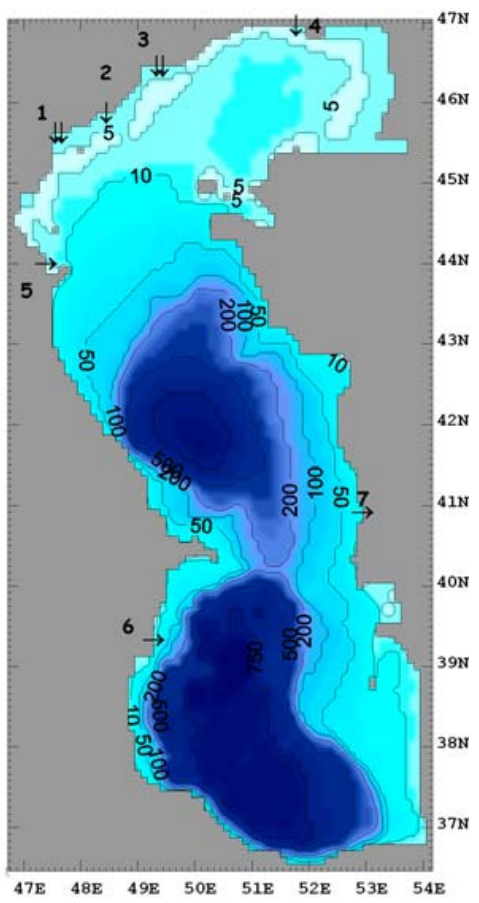

Fig. 3. Bottom topography of the Caspian Sea (depths in meters) used in the model. Arrows indicate locations of open lateral boundaries, which include branches of the Volga river: 1 - Bakhtemir (Volga); 2 - Kamyzjak (Volga); 3 - Buzan (Volga), and 4 - Ural; 5 - Terek; 6 - Kura; 7 - outflow to Kara-Bogaz-Gol.

$\left.a_{m b}, a_{h 0}, a_{h b}\right)=(50 ., 1 ., 10 ., 0.02) \times 10^{-4} \mathrm{~m}^{2} \mathrm{~s}^{-1}, \alpha=1, n=1$, $A_{m}=150 \mathrm{~m}^{2} \mathrm{~s}^{-1}, A_{h}=0.1 \mathrm{~m}^{2} \mathrm{~s}^{-1}$. The time step of integration was $30 \mathrm{~min}$.

We run the model for four years with perpetual seasonal forcing, to ensure that the basin averaged kinetic energy, temperature and general circulation reach quasi-stationary periodical states.

\section{External forcing}

Data and analyses on hydro-meteorological conditions in the Caspian Sea region are available in the Russian literature, although the data are often not on regular time-space grid. Especially standing out among these sources is the "Complex hydro-meteorological Atlas of the Caspian and Aral Seas" edited by Samoilenko and Sachkova (1963), including charts of monthly mean air-sea fluxes. As many later publications have done, we have accepted this Atlas as a key reference. Yet, because of the need to assess synoptic and inter-annual variability of the Caspian Sea, digital data produced by NCEP/NCAR and ECMWF re-analysis projects, continuously covering several decades at regular grids of $1.875^{\circ}$ and $1.125^{\circ}$ respectively, were found to be more suitable. Comparison with climatologic analyses of Samoilenko 


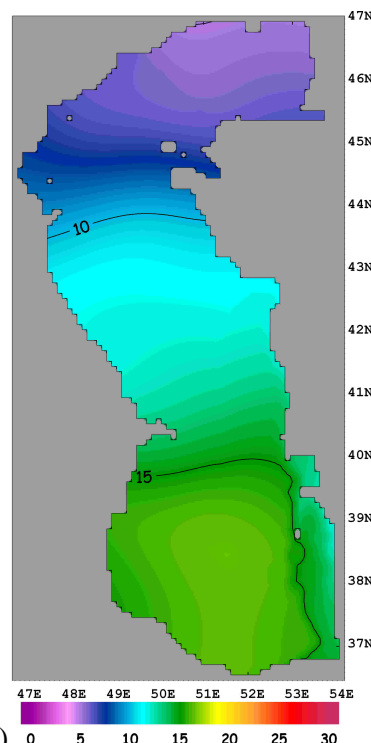

(a) $\begin{array}{lllllll}0 & 5 & 10 & 15 & 20 & 25 & 30\end{array}$

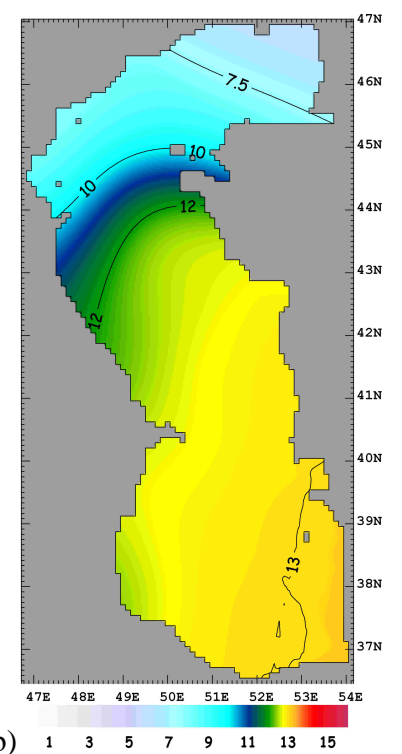

Fig. 4. Monthly mean sea surface (a) temperature $\left({ }^{\circ} \mathrm{C}\right)$ and (b) salinity (psu) based on climatology for November (Ibrayev, Sarkisyan, and Trukhchev, 2001).

and Sachkova (1963) showed that the NCEP/NCAR were far from climatic charts, while the ECMWF ERA15 data were very close. Although the resolution of the atmospheric data (only 11 cells) was not very good, the better agreement of wind fields and air-sea fluxes with climatology, both in geographical and seasonal distribution, and similar comparisons for the adjacent Black Sea (Schrum et al., 2001) convinced us that the ERA15 data would be the best choice.

The model forcing is computed from monthly mean atmospheric surface variables based on the ECMWF ERA15 reanalysis data (wind velocity at $10 \mathrm{~m}$ height, air and dew point temperatures at $2 \mathrm{~m}$ height, incoming solar radiation and thermal back radiation).

We simulate the seasonal dynamics by applying perpetual yearly forcing corresponding to a selected year. Since drastic sea level changes in the last two decades have resulted from imbalances in the external forcing, we select a year with the lowest net sea level change in the period of interest covered by the ECMWF data. Analyses of hydrometeorological data from Makhachkala, Fort-Shevchenko, Krasnovodsk and Baku indicate 1982 to be a year with smallest change in mean sea level, amounting to about $+6.75 \mathrm{~cm}$ from January till December, as shown in Fig. 2. For testing the validity of ECMWF ERA15 data we compare them with climatologic data and statistics from hydrometeorological atlases of Samoilenko and Sachkova (1963) and the books of Kosarev and Yablonskaya (1994) and Terziev et al. (1992) (hereinafter briefly referred to as SS, KY, and TKK).

Monthly mean river runoff data were obtained from routine hydrometeorological observations.

\subsection{Atmospheric forcing}

\subsubsection{Air temperature and humidity}

The characteristic air temperature patterns in winter and summer are shown in Fig. 5. In winter, the temperature has a meridional gradient, decreasing from about $+8^{\circ} \mathrm{C}$ in the SCB to $-10^{\circ} \mathrm{C}$ in the $\mathrm{NCB}$, with a local minimum near the mountainous west. Air temperature in July has a zonal gradient resulting from contrasts between the desert and mountain regions, increasing from about $22^{\circ} \mathrm{C}$ in the northwest to $27^{\circ} \mathrm{C}$ in the east.

Throughout the year, vapour pressure is higher in the SCB compared to the other sub-basins and also in the interior of the sea compared to the coastal regions. Maximum vapour pressure occurs in July, reaching values of $27 \mathrm{mb}$ and $23 \mathrm{mb}$ respectively at the centers of the SCB and the $\mathrm{NCB}$, and decreasing to $11-15 \mathrm{mb}$ along the eastern coast. In February, the vapour pressure decreases from $8 \mathrm{mb}$ at the center of SCB to $1-2 \mathrm{mb}$ in the NCB and in the coastal regions.

Monthly mean air temperature and vapour pressure distributions for 1982 are close to the climatology provided by TKK, except for winter in the NCB, where air temperature from ECMWF is $3-5^{\circ} \mathrm{C}$ higher than the values given by the climatology.

\subsubsection{Wind}

The wind speed is typically about $4 \mathrm{~m} / \mathrm{s}$ during the summer and increases up to $5-6 \mathrm{~m} / \mathrm{s}$ in winter. Wind speed in winter increases from south to north, exceeding $6.5 \mathrm{~m} / \mathrm{s}$ in the north (Fig. 6a). In summer the maximum wind speed occurs to the east of the Apsheron peninsula. The annual cycle of the monthly mean wind can be divided into three periods: a) December-January with convergence of winds in the $\mathrm{MCB}$ and SCB resulting from the high land-sea temperature contrast in winter, producing local cells of atmospheric circulation with upward motion of the relatively warmer air in the middle of the basin (Fig. 6a). b) February-July when large-scale anti-cyclonic winds prevail over the Sea (Fig. 6b), with south south-southwest-ward winds and divergence in the SCB. The local atmospheric circulation in summer in the SCB appears to be the opposite of the winter situation, as a result of the reversed land-sea temperature differences, when the land temperature in the surrounding deserts and steppes exceed $30-40^{\circ} \mathrm{C}$, while the sea is relatively cooler. c) August-November, when average wind direction gradually changes from south-, southwest-ward to westward.

Substantial agreement is observed between monthly mean winds computed from the ECMWF reanalysis data for 1982 and the climatologic winds provided by SS on the basis of measurements made at ships and 72 coastal meteorological stations. The consistency between the climatologic means of SS from the 1950's and those derived from ECMWF ERA15 


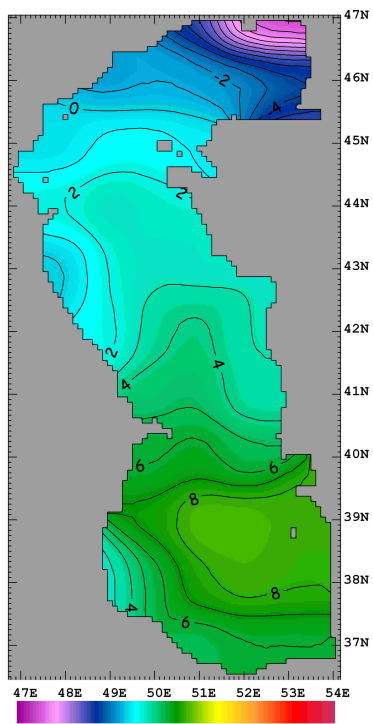

(a) $\begin{array}{rlllllllll}-15 & -10 & -5 & 0 & 5 & 10 & 15 & 20 & 25 & 30\end{array}$

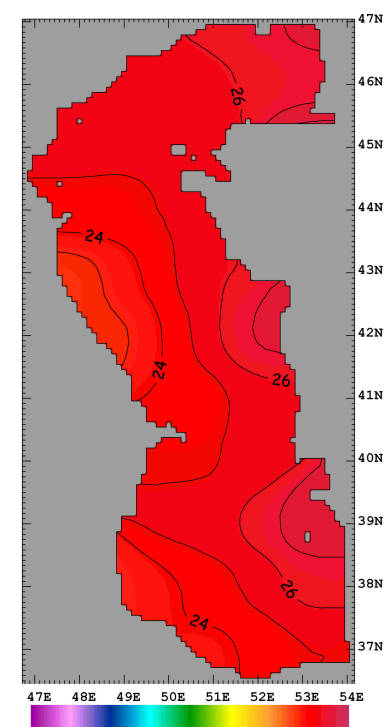

(b) $-15 \begin{array}{lllllllll}-10 & -5 & 0 & 5 & 10 & 15 & 20 & 25 & 30\end{array}$

Fig. 5. Air temperature $\left({ }^{\circ} \mathrm{C}\right)$ at $2 \mathrm{~m}$ height in (a) February and (b) July of 1982, based on the ECMWF ERA15 data set.

data for the 1980's suggest relatively small climatic change in the character of winds during the 30 years.

\subsubsection{Precipitation}

Precipitation over the sea is extremely non-uniform. The southwest receives up to 10 times more rainfall compared to the rest of the basin with a maximum in October and November (Fig. 7a). A maximum value $238 \mathrm{~mm} / \mathrm{month}$ in November 1982 occurs in the ECMWF data, while the climatologic data of SS and TKK respectively indicate $300 \mathrm{~mm} / \mathrm{month}$ and $255 \mathrm{~mm} / \mathrm{month}$, both being in October. Summer time rainfall in the western part of SCB is normally about $30-40 \mathrm{~mm} / \mathrm{month}$ (Fig. $7 \mathrm{~b}$ ), but almost completely vanishes in some years. The annual mean precipitation of $340 \mathrm{~mm} / \mathrm{month}$ in 1982 is close to the maximum value of $366 \mathrm{~mm} / \mathrm{month}$ in 1993 , and much greater than the minimum of $247 \mathrm{~mm} / \mathrm{month}$ in 1986. Large-scale precipitation based on ECMWF reanalysis data shows good correlation with the 1900-1960 rainfall data of SS and with the climatologic data of TKK.

\subsubsection{Radiation fluxes}

Radiation flux for the Caspian Sea has a minimum in December and a maximum that typically occurs in June (Fig. 8). The most distinguishing feature of the net radiation flux pattern is the decrease from west to east in summer. The annual mean net radiation flux (defined by the sum of solar and thermal radiation fluxes) is $73 \mathrm{Wm}^{-2}$ for the ECMWF data set, which is lower than the climatologic estimates of SS $\left(79.7 \mathrm{Wm}^{-2}\right)$ and of TKK, the latter one having 101$136 \mathrm{Wm}^{-2}$ for different parts of the sea. Annual radiation
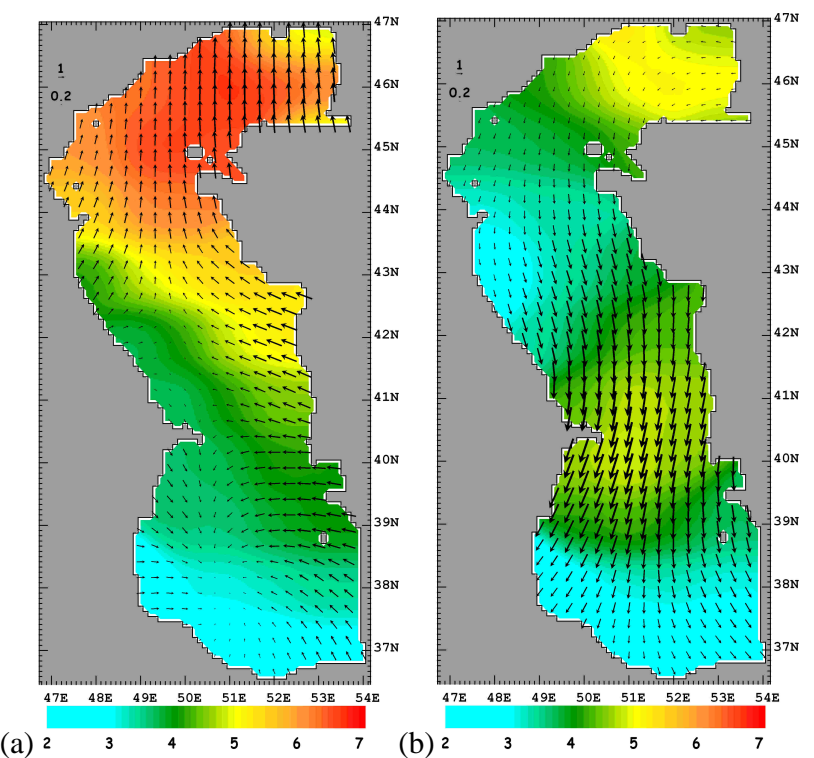

(a) 2

Fig. 6. Monthly mean wind velocity vectors and wind speed isolines in (a) December and (b) July 1982, based on the ECMWF ERA15 data set. The units are in $\mathrm{m} / \mathrm{s}$.

flux in 1982 is the lowest in the analysed period, which has a maximum of $76.8 \mathrm{Wm}^{-2}$ in 1985 .

The radiative heat flux plays an important role in the heat and water budgets of the Caspian Sea. Because the net radiation flux of ECMWF reanalysis is lower than the climatological estimates, we have increased the solar radiation by $5 \%$ to yield a corrected annual mean net radiation flux of $80.6 \mathrm{Wm}^{-2}$, a value close to estimate of SS. The sensitivity of the model to radiation flux is further discussed in the following sections.

\subsubsection{River forcing}

The largest inflow of fresh water comes from the Volga River, accounting for about $80 \%$ of the climatological mean river discharge of $250 \mathrm{~km}^{3} \mathrm{yr}^{-1}$ (Kosarev and Yablonskaya, 1994). The mass, momentum and buoyancy inputs from the Volga River all play important roles in the dynamics of the sea. The three main branches of the Volga river delta are idealized in the model as shown in Fig. 3. All other sources of freshwater with net annual water flux greater than $10 \mathrm{~km}^{3} \mathrm{yr}^{-1}$, namely the Ural, Terek and Kura rivers are represented by their corresponding discharges of fresh water. The Kara-Bogaz-Gol on the arid eastern coast acts as an important sink in the water balance, largely as a shallow evaporation basin connected to the sea. After the dramatic drop in sea level in the late 70-ies the outflow to KaraBogaz-Gol was blocked to remedy water loss. The dam was in place from 1980 till 1984, and was opened later. So in 1982 there was no outflow to Kara-Bogaz-Gol Bay. Altogether, lateral fluxes are specified at 7 input/output ports in 


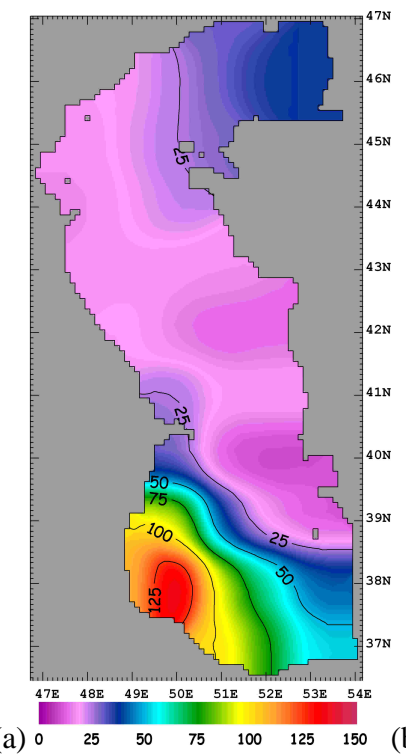

(a) 0

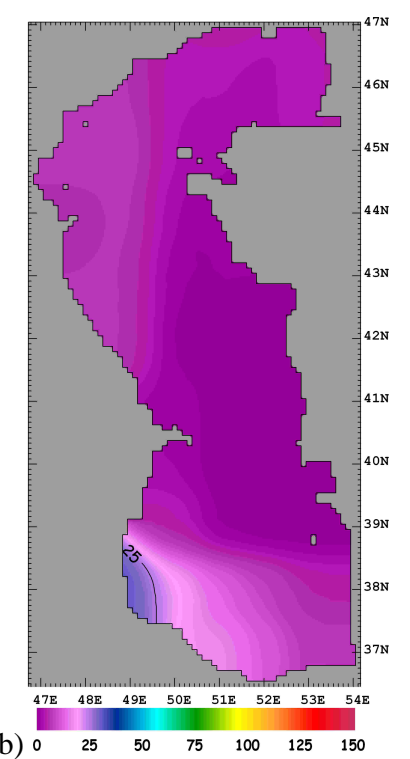

Fig. 7. Precipitation (mm/month) in (a) January and (b) August of 1982, based on the ECMWF ERA15 data set.

the model. Monthly mean runoff for 1982 are specified for the Volga, Ural, Terek and Kura rivers. Water temperature at all rivers was taken to be the same as the Volga River, using averages for the 1960-1990 period at the Verkhnee Lebjazhie station, reported in the Water Cadastral Reference book of the USSR Rivers. Seasonal variability in Volga river runoff is extremely high. From July till April, the Volga River discharge is about $5000-6000 \mathrm{~m}^{3} \mathrm{~s}^{-1}$. A sharp increase in runoff of up to $15500 \mathrm{~m}^{3} \mathrm{~s}^{-1}$ occurs in May-June during the spring flood. Different estimates show that up to $3-5 \%$ of Volga runoff measured at the Verkhnee Lebjazhie station, located upstream of the delta, is lost due to evaporation in the vast delta of the river (Terziev et al., 1992). To account for this loss, we corrected the Volga river runoff, assuming that the river discharge at the coast amounted to $96 \%$ of the inland measurements.

\section{Model results}

We first consider a basic experiment, and in a later section analyse the sensitivity of the model to external forcing and model parameters. Only the monthly averaged fields are presented in the following, in order to filter out short-term fluctuations and concentrate on the seasonal evolution.

\subsection{Seasonal variability of the Caspian Sea dynamics}

\subsubsection{Three dimensional currents}

Monthly mean currents at $1 \mathrm{~m}$ depth in December, May and August in Fig. 9 exhibit the dominant seasonal patterns of the surface circulation. In December and January, sub-basin-
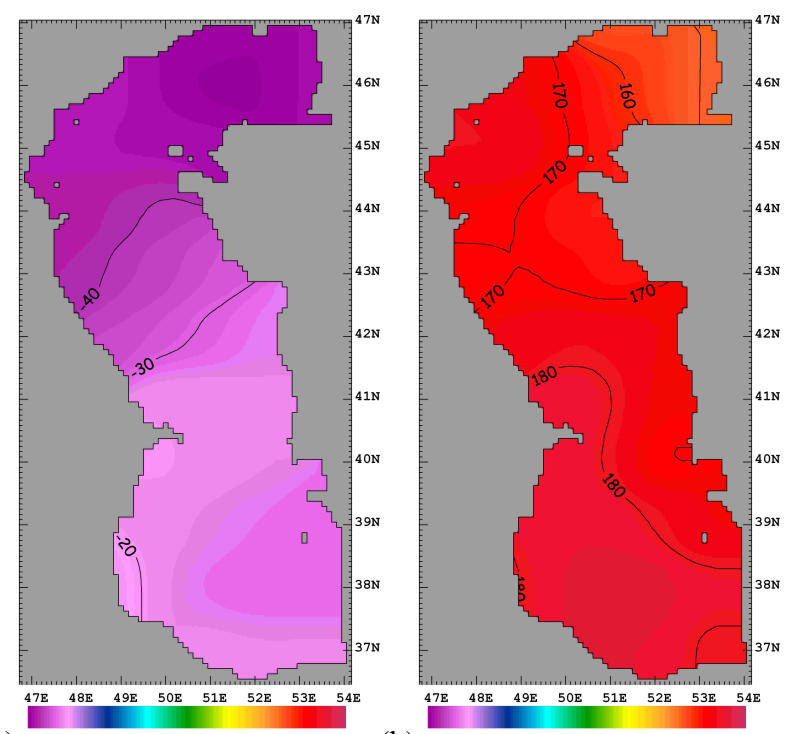

(a) $-50-25 \quad 0 \quad 25 \quad 50 \quad 75100125150175200$

(b) $-50-250 \begin{array}{lllllll}25 & 50 & 75 & 100125150175200\end{array}$

Fig. 8. Surface net radiation flux $\left(\mathrm{Wm}^{-2}\right)$ in (a) December and (b) June of 1982, based on the ECMWF ERA15 data set.

scale cyclonic gyres entirely cover the MCB and SCB, while a number of anti-cyclonic and cyclonic eddies are found in the NCB. This pattern of surface currents is expected, in view of the strong westward wind along the eastern coast and the convergence areas in Fig. 6a. The subsurface (25$100 \mathrm{~m}$ depth) circulation (Fig. 10) in December and January correlates well with the surface circulation patterns of Fig. 9. Both the MCB and the SCB are occupied by cyclonic gyres connected across the Apsheron sill. Deeper circulation plots reveal that the currents become weaker with depth but preserve their structure all the way to the bottom.

In comparison to the earlier month of December displayed in Fig. 9, the surface circulation first becomes significantly different in February (not shown), when the wind direction changes to become southward in the MCB and SCB. As shown by the May circulation in Fig. 9b, the cyclonic gyre in the SCB is shifted to the south and the cyclonic gyre in the MCB disappears. South-southwestward Ekman drift currents dominate the deep-sea regions, superposed on southward coastal currents along the eastern and western shelf regions. The main features of the circulation in May is representative of the period from February till July, which indicates additional small changes in currents along the eastern part of the NCB and cyclonic and anticyclonic eddies near the NCB-MCB boundary.

In February and March the subsurface circulation is gradually modified to become more like Fig. 10b, a pattern which is characteristic of the warm period from April till October. The main differences from the cold period are the appearance of anticyclonic eddies west of the MCB and northwest and south of the SCB with a corresponding decrease in the sizes of cyclonic eddies. Below the depth of Apsheron sill 

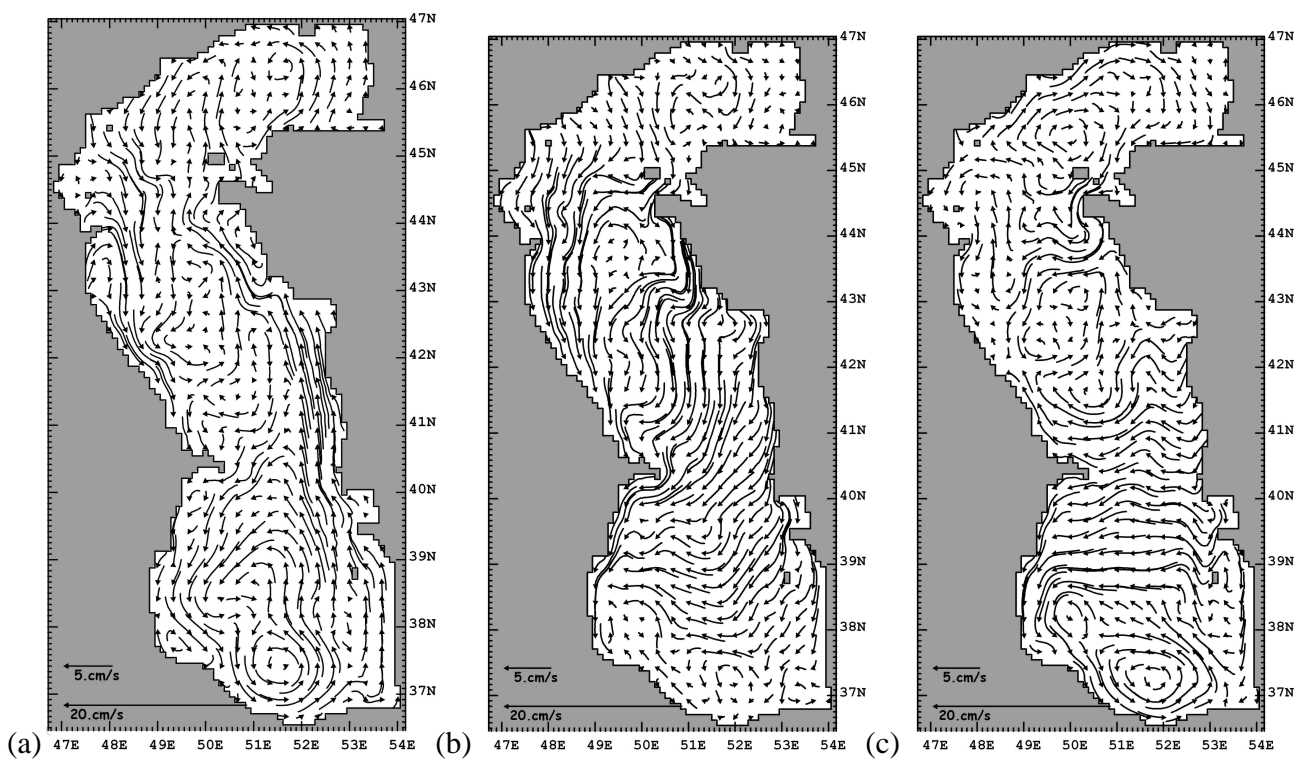

Fig. 9. Monthly mean sea surface currents $(\mathrm{cm} / \mathrm{s})$ for the months of (a) December, (b) May and (c) August.

(a)
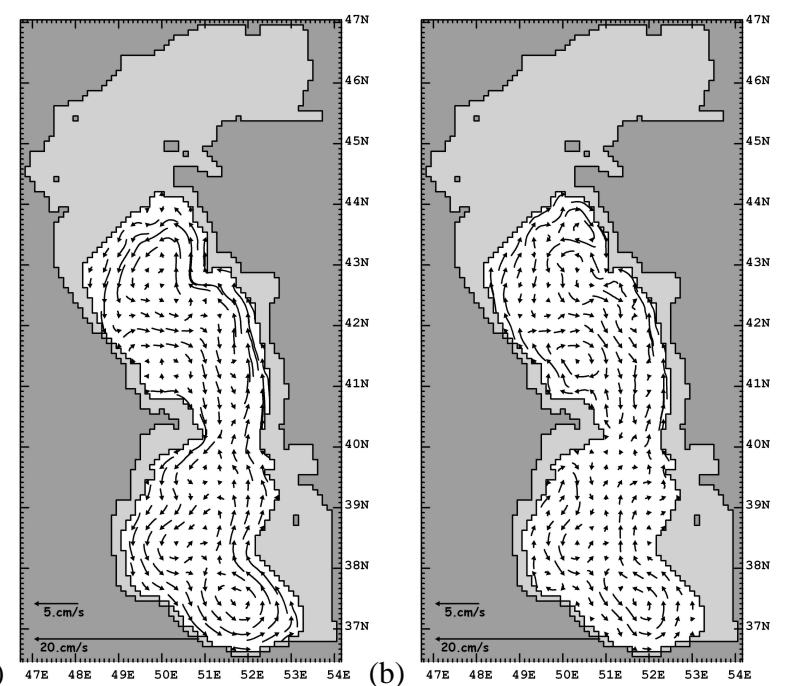

Fig. 10. Monthly mean currents $(\mathrm{cm} / \mathrm{s})$ at $50 \mathrm{~m}$ depth for (a) December, (b) May.

(not shown), the cyclonic circulation is preserved in the SCB ( $\sim 2 \mathrm{~cm} / \mathrm{s}$ at $300 \mathrm{~m}$ depth), but becomes much weaker in the MCB.

Of particular interest is the presence of southward coastal currents along either the eastern and western coasts. Both current systems are dominant from February till July, when the wind-induced southwestward drift currents at the surface result in offshore transport near the east coast and onshore transport near the west coast, resulting in upwelling and downwelling respectively on these coasts to compensate the surface drift. Both current systems span the con- tinental shelf/slope regions in the form of coastal jets studied by Csanady (1982). The coastal current along the west coast and the upwelling along the east are well-documented (Terziev et al., 1992; Kosarev and Yablonskaya, 1994), but often conflicting evidence is found on the eastern coastal current, as a result of its poorly understood horizontal and vertical structure.

The Eastern coastal current near the surface occupies a coastal belt shoreward of the $50 \mathrm{~m}$ isobath. At a distance 50 $100 \mathrm{~km}$ from the coast, the alongshore surface current turns offshore to join the surface drift, which is compensated by onshore motion in the subsurface layer, as shown in Fig. 11a. In the subsurface layer, slightly offshore of the core of the eastern southward coastal current, exists northward countercurrent, attached to the slope between $50-100 \mathrm{~m}$ isobaths, as shown in Fig. 11b. A very similar, but narrower subsurface current flowing northward takes place under the western coastal current. The core of the counter-current coincides with the pycnocline, which is stronger and shallower in summer.

After August, the circulation pattern is gradually modified towards the December pattern reviewed earlier. The changes in the circulation are correlated with the changes in wind direction from southward to westward in the MCB and becoming southwestward in the SCB. The earlier southwestward drift in the MCB becomes more west and northwest oriented, as indicated in Fig. 9c. In the western part of the MCB, a number of cyclonic eddies start to appear, gradually increase in size, and finally merge together to form the sub-basin scale cyclonic gyre of the MCB in December. In the same period, the eastern coastal current in the MCB becomes weaker and finally turns northward in November. The cyclonic eddy in the SCB once again fills the basin. 


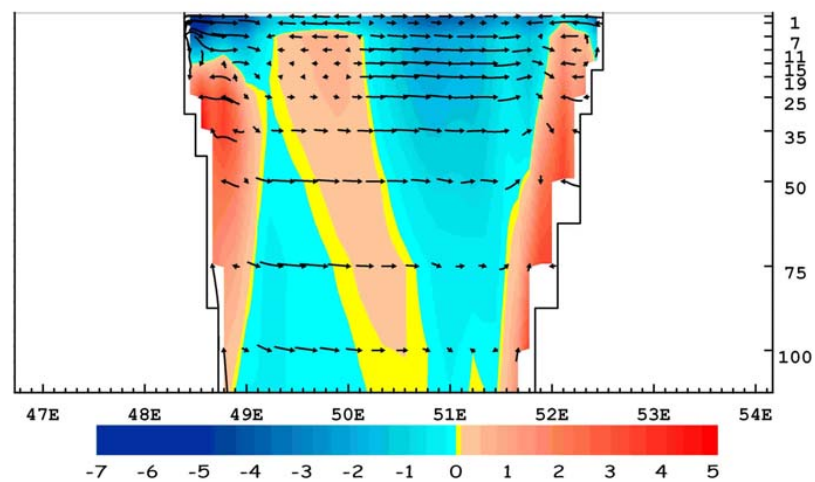

Fig. 11. Vertical cross section of currents along $42^{\circ} \mathrm{N}$ in May: (a) current vectors in the plane of the cross section, (b) isotachs of velocity component perpendicular to the section (northward is positive, southward is negative).

\subsubsection{Water mass characteristics}

In the shallow NCB, minimum SST occurs in February, when the sea is covered with ice (Fig. 12a). With a time lag, the minimum temperatures in the MCB and SCB occur in March, when the NCB starts warming. The winter time SST increases from lower temperatures near the coast to about $12^{\circ} \mathrm{C}$ in the interior of SCB. In autumn and winter, the shelf areas are always $5-6{ }^{\circ} \mathrm{C}$ cooler than the interior regions, because of the smaller heat capacity of shallow waters.

From December till March, SST in the MCB is characterised by a north-south gradient, and tongues of warm water along the eastern coast and cold water along the western coast. In December and January, these coastal SST anomalies are apparently related to the cyclonic circulation shown in Figs. 9a and 10a.

A paradox with the tongue of warm water along the eastern coast is that it does not disappear in February and March, at a time when the surface currents (Fig. 9b) are directed southward. The transport of warm water along the coast is maintained by the northward subsurface current identified earlier (Fig. 10b). The warming of surface waters is a result of two mechanisms working in parallel: the upwelling of warm subsurface vein attached to the shelf (Fig. 11a) and by vertical mixing of this warm subsurface water with colder surface water.

The west to east increase of SST in the MCB in winter is a characteristic feature of the Caspian Sea climatology (Kosarev and Yablonskaya, 1994). A tongue of warm water extending from the SCB to the MCB along the eastern shelf has been one of the supportive arguments for the existence of the northward current and, hence, of the general cyclonic circulation pattern at the sea surface. While the surface current system in MCB and SCB in December and January supports the scheme of Fig. 1, then the existence of a southerly flowing coastal current along the east coast
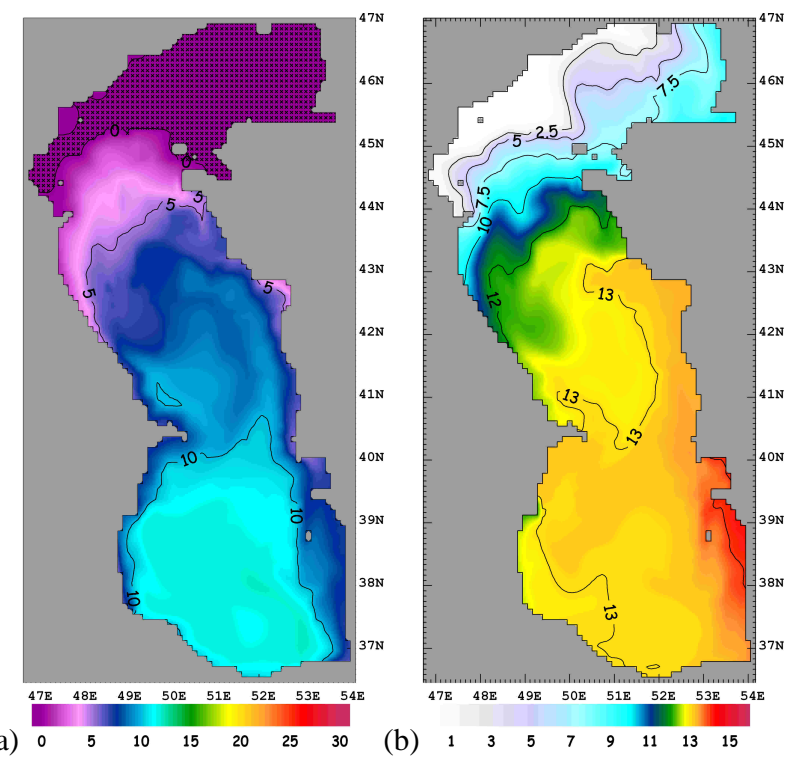

Fig. 12. Monthly mean (a) sea surface temperature $\left({ }^{\circ} \mathrm{C}\right)$ and (b) salinity (psu) in February. Dashed regions in (a) indicate presence of ice.

and offshore drift currents, at first appear totally to contradict that scheme. The above analysis shows that the warm water tongue of the eastern shelf of the MCB is produced by a more complex mechanism, i.e. the northward transport of warm water by the subsurface current, followed by upwelling and mixing between surface and subsurface waters. The existence of a northward flowing subsurface counter-current under the southward flowing surface current has been discussed by Kosarev and Yablonskaya (1994). The simulated structure of the currents along the east coast is also supported by observations made to the north of $43^{\circ} \mathrm{N}$ (Bondarenko, 1993).

The effects of freshwater input from the Volga River, intensive evaporation along the eastern coast of the SCB, combined with the southward flowing coastal current along the western coast create three major salinity fronts (Fig. 12b) in the Caspian Sea. Meeting of the saline waters from the MCB and the fresh waters discharged into the NCB by Volga as well as other rivers creates a wide front between them, further enhanced by the depth difference between the two regions. The second, less sharp, salinity front is created on the eastern shelf of the SCB. Here the interior waters meet the more saline water of the shelf produced by excessive evaporation in the region. The third, meridionally stretched front is formed in the MCB, between low salinity waters of $\mathrm{NCB}$ transported south along the west coast (also noted by Kosarev and Tuzhilkin, 1995) and the higher salinity waters of the MCB interior.

Winter mixing in the MCB and SCB is strongest in March and reaches 50-75 $\mathrm{m}$ depth in the interior regions of the MCB and 100-200 $\mathrm{m}$ along the shelf slopes (Fig. 13). Newly formed cold water with temperature of about $7-8{ }^{\circ} \mathrm{C}$ 
occupies the upper part of the basin interior, while the temperature is close to zero along the west coast. Observations of dissolved oxygen indicate large variations in the depth of convective mixing, depending on the bottom depth, location and the severity of winter. During moderate and mild winters, convective mixing is shown to reach depths of 150 $200 \mathrm{~m}$, as opposed to severe winters when it reaches all the way to the bottom of the MCB (Baidin and Kosarev, 1986).

Winter conditions in the NCB and the coastal regions of the MCB are favourable for freezing of seawater. Observations (Kosarev and Yablonskaya, 1994) indicate that ice area and thickness strongly depend on the severity of winter. In the model, ice appears in the first half of December and reaches its maximum extent in the middle of February (Fig. 14), when the NCB is totally covered by ice. Maximum ice thickness of more than $70 \mathrm{~cm}$ is reached in the beginning of March. Model simulated ice growth, i.e. features such as the start of ice formation, periods of maximum ice cover and thickness, etc. are in agreement with the available observations (Kosarev and Yablonskaya, 1994). On the other hand, comparison with climatologic data shows that the ice edge is often about $50 \mathrm{~km}$ more to the south than indicated by the model, often extending south along the eastern coast of the MCB in moderate winters such as 1982. A smaller ice covered area in the model as compared to the observations could be a result of (i) higher air temperature in the NCB obtained from ECMWF data compared to the climatology, (ii) modified heat capacity of the extremely shallow areas of the NCB, artificially made deeper due to numerical stability considerations.

As surface waters start warming in March, the temperature difference between the shelf and the deep-sea regions start to decrease. In the beginning of April, after the melting of ice, the last cold water patch remains in the north-eastern part of $\mathrm{NCB}$, undisturbed by the weak circulation in the region.

The average SST values are around $25-26^{\circ} \mathrm{C}, 22-23^{\circ} \mathrm{C}$ and $25^{\circ} \mathrm{C}$ respectively in the interior regions of the $\mathrm{NCB}$, MCB and SCB (Fig. 15). The surface waters in the shallow coastal regions of the SCB are often much warmer, especially along the eastern shelf, where the temperature approaches $30^{\circ} \mathrm{C}$ and the salinity is increased by high rates of evaporation near the desert. Cold water with temperature of $14-16^{\circ} \mathrm{C}$ appears along the eastern shelf of the MCB, in the well-known upwelling region of the Caspian Sea, as a result of the surface drift directed away from the coast. Upwelling along the east coast is a quasi-permanent circulation feature of the warm season, supported by climatologic (Kosarev and Yablonskaya, 1994) and satellite (Sur et al., 1998) observations.

The sea surface salinity distribution in spring and summer is qualitatively similar to the winter (Fig. 12b), except for the following minor differences: (i) the spring floods cause the northern salinity front to be moved by up to $50-100 \mathrm{~km}$ away from the mouth of the Volga River; (ii) the salinity front of the eastern shelf of the SCB, locked to the slope topography in winter, becomes a much wider transition zone between the saline coastal waters ( $S=15.6 \mathrm{psu}$ ) and the less saline interior waters $(S=13.2 \mathrm{psu})$. Noticeable salinity changes occur along the western coast of MCB in August, when the coastal current is deflected from the west coast and therefore the southernmost penetration of low salinity waters is limited only to as far south as $42^{\circ} \mathrm{N}$.

The surface mixed layer thickness changes from $15-25 \mathrm{~m}$ on the western coast of MCB and SCB to about $10 \mathrm{~m}$ on the eastern coast of $\mathrm{MCB}$, with essentially a two-layer density stratification developing in summer. A temperature difference of $14{ }^{\circ} \mathrm{C}$ develops across the seasonal thermocline, with the density increasing from $1067 \mathrm{~kg} \mathrm{~m}^{-3}$ in the upper layer to $1095 \mathrm{~kg} \mathrm{~m}^{-3}$ at the bottom (Fig. 16).

\subsection{Air-sea fluxes of heat and mass}

In this section we focus our attention on the seasonal airsea fluxes of heat and moisture at the air-sea interface. Our model development for the Caspian Sea is unique in many respects: Flux estimates in the past often have been based on bulk formulae using extremely non-uniform and coarse data sets. We implement a more rigorous, interactive flux estimation scheme making use of oceanic and atmospheric surface properties respectively obtained from the Caspian Sea model and the ECMWF reanalysis atmospheric model relying on global data assimilation. A thermodynamic sea ice model is further used to modify the surface fluxes when ice is formed. The requirement for mass conservation is relaxed in the model to account for a non-zero water budget of the sea with respect to the river and surface volume fluxes.

Estimation of surface heat flux from bulk formulae using monthly mean values of surface wind speed, humidity, air and sea surface temperature, has been shown to differ by less than $10 \%$ from computations using all samples by Esbensen and Reynolds (1981), and has been confirmed to have a ratio of 1.02-1.09 for different parts of the Caspian Sea by Panin (1987). We thus employ a correction factor of 1.09 for sensible and latent heat fluxes computed from monthly fields.

\subsubsection{Evaporation}

In winter, a region of high evaporation in the eastern part of MCB (Fig. 17a) results from the combined effects of (i) cold and dry air intrusions from the eastern coast and (ii) warm water from the SCB advected along the eastern coast. The summer evaporation pattern is the opposite (Fig. 17b): the cold water along the eastern shelf of MCB produces very little evaporation. Evaporation in summer has an increasing trend from north to south, except in the shallow NCB where evaporation is increased to almost twice the deep basin values. Analyses of monthly mean evaporation in the Caspian Sea made on the basis of 150000 observations (Panin, 1987) are in good agreement with the simulated evaporation both 


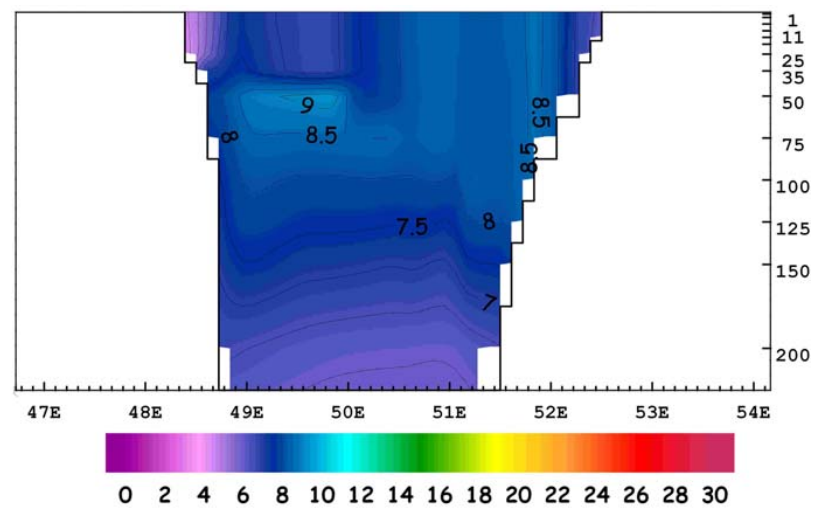

Fig. 13. Vertical cross section of temperature along $42^{\circ} \mathrm{N}$ in March.

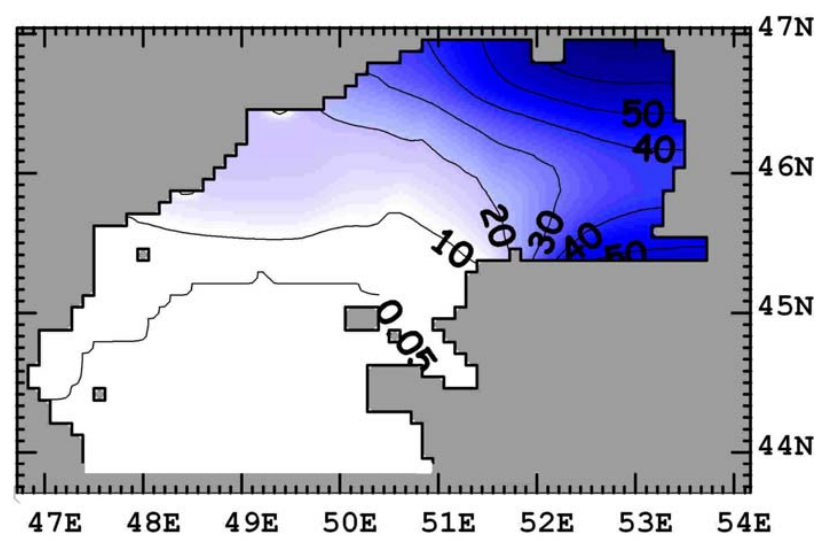

Fig. 14. Sea ice thickness $(\mathrm{cm})$ in February.

in terms of distribution and magnitude. For example, for the eastern part of MCB, Panin gives $E=100-110 \mathrm{~mm} / \mathrm{month}$ in January and $E<40 \mathrm{~mm} /$ month in July, which are consistent with our estimates. On the other hand, Panin's estimate of $E>180 \mathrm{~mm} / \mathrm{month}$ in June-August in the southern part of the SCB is much higher than ours in the same region. The reason can be due to (i) the need for better space-time resolution of atmospheric dynamics especially in SCB, where the sea is surrounded from the west and south by mountains and from east by flat deserts; (ii) the fact that we simulate a single year while Panin gives climatology; (iii) estimates of climatological fluxes are usually based on ship data which are rather non-uniform in space and time.

\subsubsection{Sensible and latent heat fluxes}

Monthly and annual mean heat budget components are given Table 1 . In the annual mean budget, heat influx by solar radiation, amounting to $160.4 \mathrm{~W} / \mathrm{m}^{2}$, is balanced by the outgoing thermal radiation $\left(-79.8 \mathrm{~W} / \mathrm{m}^{2}\right)$, latent heat $\left(-69.9 \mathrm{~W} / \mathrm{m}^{2}\right)$ and sensible heat $\left(-10.4 \mathrm{~W} / \mathrm{m}^{2}\right)$ flux components.

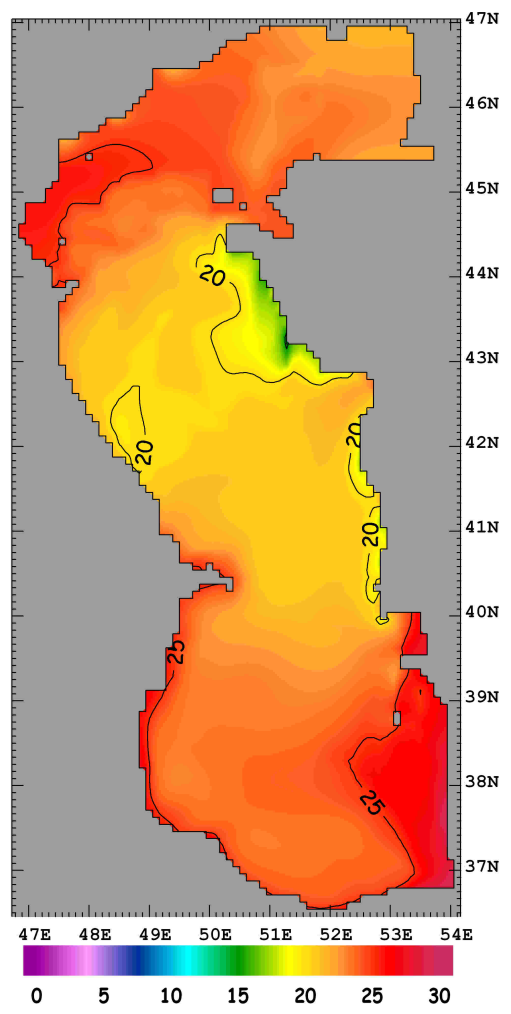

Fig. 15. Sea surface temperature $\left({ }^{\circ} \mathrm{C}\right)$ in July.

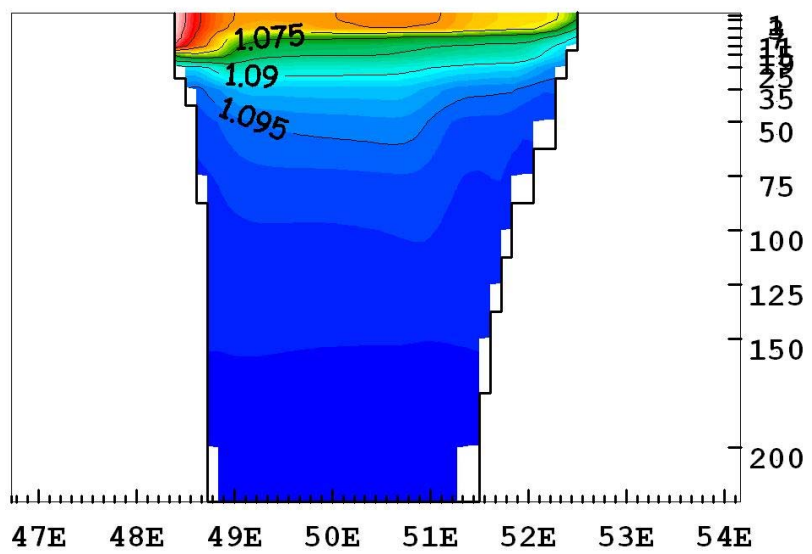

Fig. 16. Vertical cross section of sea water density $\left(\mathrm{kg} \mathrm{m}^{-3}\right)$ along $42^{\circ} \mathrm{N}$ in July.

The seasonal cycle of latent heat flux follows that of evaporation. In summer the sensible heat flux almost vanishes as a result of the small difference between SST and air temperature. SST is higher than the air temperature in the NCB and SCB (Panin, 1987), while in the MCB, SST is usually lower than the air temperature as a consequence of upwelling. Sensible heat flux becomes relatively more significant in the heat budget in the autumn and winter seasons, when it is close to the net radiative heat flux. 

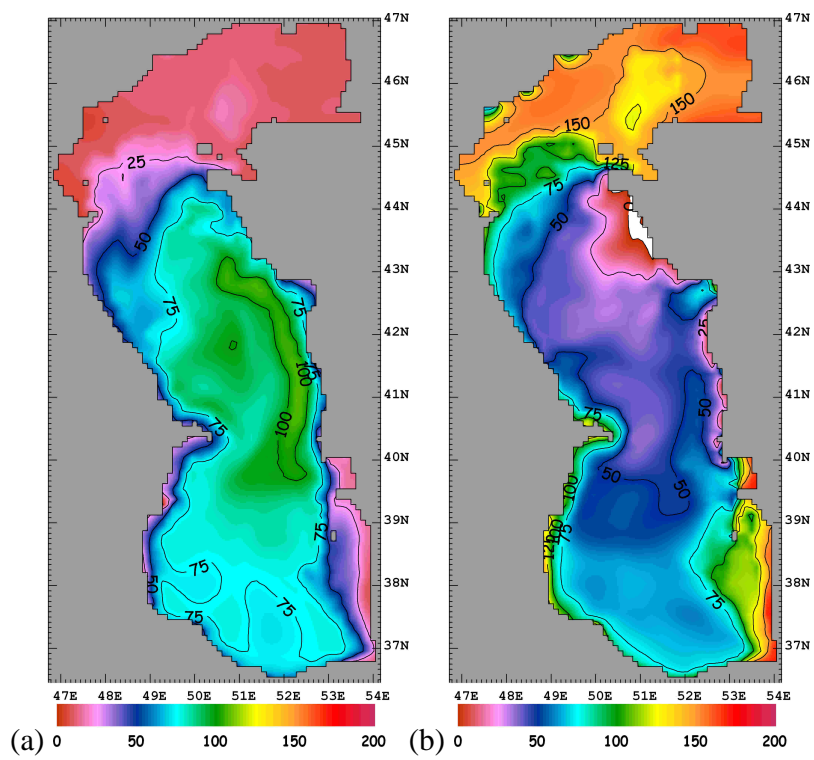

Fig. 17. Evaporation (mm/month) in (a) January and (b) July.

In winter, the turbulent heat flux (sum of sensible and latent heat fluxes) at the sea surface (Fig. 18a) has a maximum along the east coast of the MCB, produced by the interaction of the warm water tongue with overlying cold air (Figs. 5a and 12a). In this area both terms of the turbulent heat flux are of the same order $\left(-250 \mathrm{~W} / \mathrm{m}^{2}\right.$ for latent and $-150 \mathrm{~W} / \mathrm{m}^{2}$ for sensible heat flux), whereas in other parts of the sea, latent heat flux is often 2-5 times larger than the sensible heat flux. In July (Fig. 18b), sensible heat flux in the same area decreases to about $(-10)-(+20) \mathrm{W} / \mathrm{m}^{2}$ and latent heat flux dominates in total flux.

\subsection{Sea level variability and water budget}

\subsubsection{Mean sea level variability}

Time series of model simulated and observed sea level anomaly at four Caspian Sea stations are shown in Fig. 19 for the year 1982. Station locations are shown in Fig. 20. Common features of the sea level time series at all four stations are the minimum in September-October, the rising trend from autumn to spring, followed by the fall in summer. There is a net rise in sea level at the end of the presented one year period because the sea level is on a rising trend in the longer term. Good correlation in terms of amplitude and of phase between simulated and observed sea level demonstrates the model capability to reproduce key hydro- and thermo-dynamical processes of the Caspian Sea, of which the sea level is an integral measure. Root mean square difference between the simulated and observed curves changes from $1.4 \mathrm{~cm}$ at Baku to $3.0 \mathrm{~cm}$ at Krasnovodsk stations, representing $6 \%$ and $13 \%$ of the annual sea level amplitude at the respective sites.

\subsubsection{Spatial variability of the sea surface topography}

The leading factors creating the observed spatial structure of sea surface topography in the model are baroclinicity and wind setup. Although the atmospheric forcing is variable in space and time, the following features emerge from a study of the seasonal cycle: (i) east-west asymmetry in buoyancy resulting from the distribution of fresh water flux components (run-off, precipitation and evaporation). All major rivers enter the sea along the northwest coast. In the absence of other forcing, the fresh water introduced by the Volga River tends to flow along western coast, as a result of deflection by the Coriolis force. Precipitation and evaporation over the sea are extremely non-uniform. The southwest part of the SCB receives rainfall that is up to 10 times greater than the other parts of the sea (Fig. 7), while the evaporation has somewhat smoother variation over the basin. (ii) The predominant southward winds in the MCB and SCB are favourable for drifting surface water off the eastern coast, thus producing typical coastal upwelling of cold and saline sub-surface waters along this coast. All of the above factors support asymmetrical distribution of salinity, yielding high density waters on the eastern shelf and relatively low density waters on the north and southwest parts of the sea, supporting the model produced west-east slope of the sea surface topography in Fig. 20. The spatial range of sea surface topography is minimum in July $(7.5 \mathrm{~cm})$ and maximum in December $(15 \mathrm{~cm})$, which is 2-3 times smaller then the seasonal range of sea level variations.

\subsubsection{Water budget}

Estimates of Caspian Sea water balance terms based on various sources (Table 2) do not differ significantly from each other. The model simulated evaporation rate, of $86.5 \mathrm{~cm} / \mathrm{yr}$, is close to the estimate of Bortnik and Nikonova (1992) for the period 1978-1990 and to the climatologic estimate of $96.3 \mathrm{~cm} / \mathrm{yr}$ of Panin (1987).

The river runoff in 1982 was lower than the other years, amounting to only $73 \%$ of mean runoff value for the 1978 1990 period. It should be noted that inter-annual variability of river runoff is extremely high. For example, the difference between maximum and minimum yearly runoff in the last century is about $260 \mathrm{~km}^{3} / \mathrm{yr}$ or more than $100 \mathrm{~cm} / \mathrm{yr}$ in terms of sea level rise (Bortnik et al., 1992).

Low river runoff in 1982 is compensated by high precipitation. The ECMWF reanalysis data for 1982 gives a value $28 \%$ higher than the estimates of Bortnik et al. (1992) for the 1970-1977 and 1978-1990 periods. Precipitation in ECMWF reanalysis actually could have been underestimated, if one takes into account similar estimates elsewhere at around the same latitude, yielding $20 \%$ less precipitation compared to observations (Betts et al., 1999).

Underground water flux into the sea is the least known component of the water balance, with different authors' esti- 
Table 1. Monthly mean heat flux components $\left(\mathrm{W} / \mathrm{m}^{2}\right)$ at the sea surface. $Q_{s}=$ incoming solar radiation, $Q_{b}=($ long wave $)$ thermal radiation, $Q_{s}+Q_{b}=$ total radiative heat flux, $H=$ sensible heat flux, $L E=$ latent heat flux, $Q=$ total heat flux.

\begin{tabular}{lrrrrrr}
\hline Month & $Q_{s}$ & $Q_{b}$ & $Q_{s}+Q_{b}$ & $H$ & $L E$ & $Q$ \\
\hline 1 & 65.1 & -79.2 & -14.0 & -22.6 & -59.2 & -95.8 \\
2 & 94.4 & -76.5 & 17.9 & -23.2 & -57.3 & -62.7 \\
3 & 146.3 & -72.9 & 73.5 & -4.9 & -38.3 & 30.3 \\
4 & 208.3 & -68.0 & 140.3 & 4.3 & -25.7 & 118.8 \\
5 & 247.9 & -73.5 & 174.4 & -2.3 & -43.5 & 128.6 \\
6 & 269.5 & -84.7 & 184.8 & -0.3 & -63.1 & 121.4 \\
7 & 257.1 & -84.4 & 172.7 & 0.9 & -76.0 & 97.5 \\
8 & 228.9 & -91.7 & 137.2 & -1.8 & -109.9 & 25.5 \\
9 & 175.7 & -90.5 & 85.2 & -7.4 & -109.6 & -31.9 \\
10 & 108.7 & -79.7 & 29.0 & -21.6 & -109.9 & -102.4 \\
11 & 65.9 & -73.4 & -7.6 & -27.5 & -90.2 & -125.2 \\
12 & 57.0 & -82.6 & -25.6 & -18.6 & -56.7 & -100.8 \\
Annual mean & 160.4 & -79.8 & 80.6 & -10.4 & -69.9 & 0.3 \\
Standard deviation & 77.5 & 7.0 & 84.5 & 10.9 & 27.9 & 94.4 \\
\hline
\end{tabular}
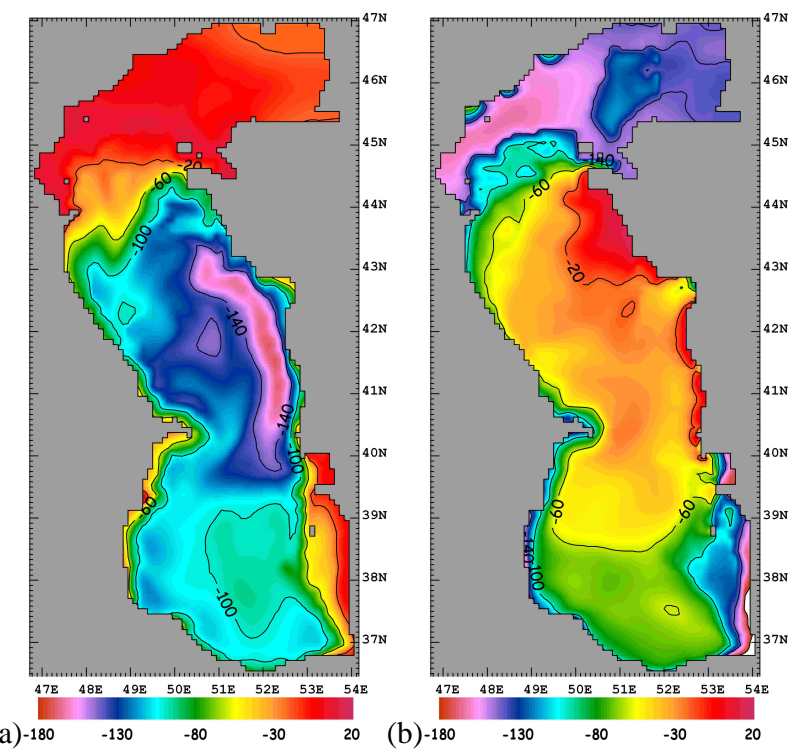

Fig. 18. The sum of sensible and latent heat fluxes in $\left(\mathrm{W} / \mathrm{m}^{2}\right)$ in (a) January and (b) July.

mates in the range 0.3 to $49.3 \mathrm{~km}^{3} / \mathrm{yr}$ (Bortnik et al., 1992). As most estimates are relatively small, on the order of 3$5 \mathrm{~km}^{3} / \mathrm{yr}$ or about $1 \mathrm{~cm} / \mathrm{yr}$ of mean sea level change, ground water inflow was not taken into consideration in the model.

In Table 2, we compare sea level increment estimated for 1982 based on observed river runoff together with ERA15 precipitation - evaporation with that obtained from the model solution. In the model we have found the annual increment to be $+7.0 \mathrm{~cm}$, while the estimate based on river runoff observation and ERA15 data is $2.2 \mathrm{~cm}$. The difference of $9.2 \mathrm{~cm} / \mathrm{yr}$ between ECMWF estimated $(-2.2 \mathrm{~cm})$ and model $(+7.0 \mathrm{~cm})$
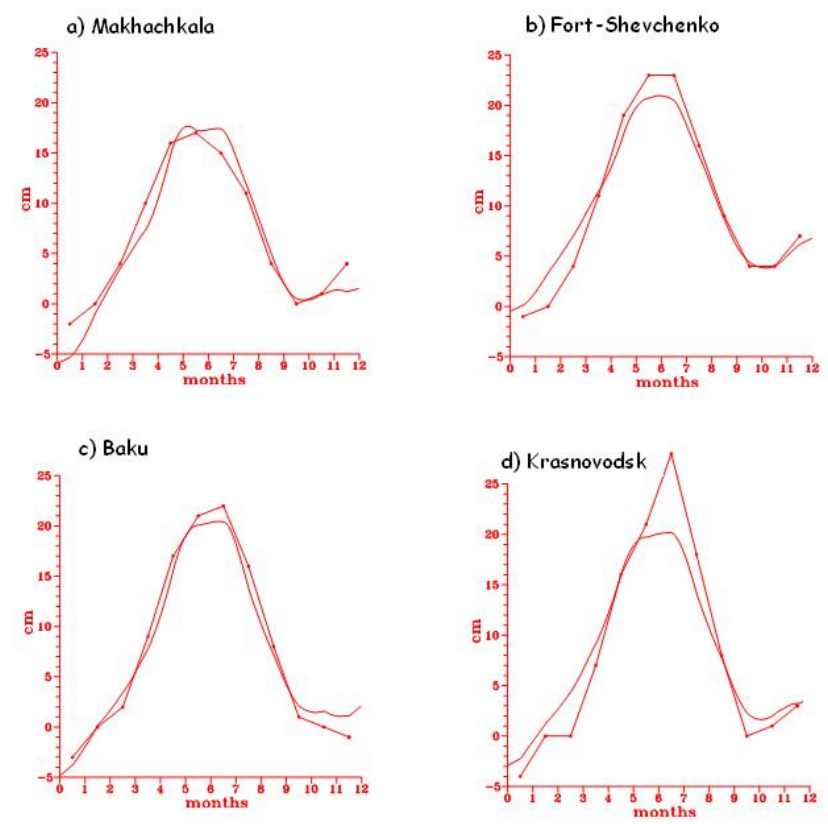

Fig. 19. Sea level anomaly $(\mathrm{cm})$ in 1982 at different locations around the Caspian Sea: (a) Makhachkala; (b) Fort-Shevchenko; (c) Baku and (d) Krasnovodsk. Smooth curves show model results and the broken lines correspond to observations.

sea level change gives a measure of error of the modern estimations of the water balance.

\section{Sensitivity experiments}

As already pointed out, the water budget of Caspian Sea is extremely sensitive to climatic variability. In fact, the present 


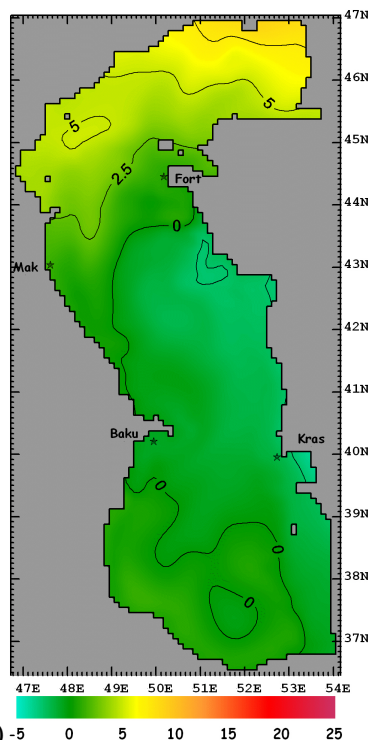

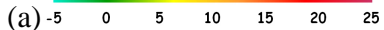

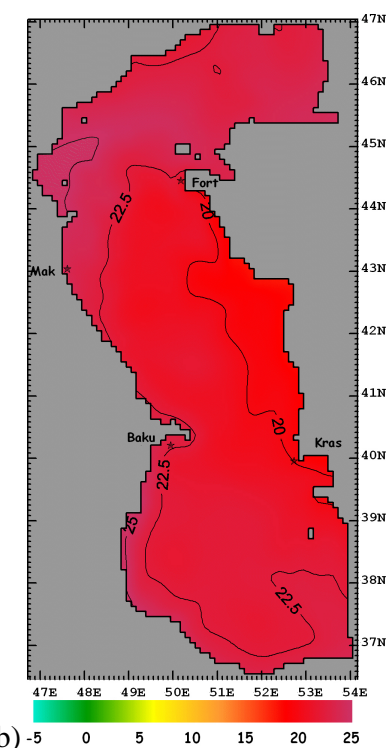

Fig. 20. Sea surface topography $(\mathrm{cm})$ in (a) January and (b) June. The locations of hydrometeorological stations Makhackala (Mak), Fort-Shevchenko (Fort), Baku and Krasnovodsk (Kras) are also indicated.

sea level variations are much smaller than the contributing terms of river runoff, precipitation and evaporation, which tend to balance each other. Therefore, small differences in water budget components can lead to large changes in sea level. It is a widespread opinion that inter-annual variability of sea level is controlled by river runoff while anomalies of precipitation and evaporation have less impact on the range of sea level fluctuations (Rodionov, 1994).

A set of experiments was performed to ascertain the sensitivity of the circulation and sea level change to external forcing and model parameters. We refer to the above experiment with the parameters and forcing given earlier, as the control run (CR). In the following experiments, we have run the model with further variations in model parameters and of external forcing, using the beginning of the fourth year of the $\mathrm{CR}$ as initial conditions.

In the first two experiments we examine the sea level change and circulation in response to variations in prescribed water budget components, i.e. river runoff and precipitation. Next are the experiments with variations of atmospheric parameters, which determine the evaporative flux, i.e. the air and dew point temperature, and wind speed. In further experiments we describe the sensitivity of the model to solar radiation and to parameterisation of the solar radiation penetration into the sea. In the last experiment, we analyse the sensitivity of the model to variations of vertical mixing. In most of these sensitivity experiments we have implemented external forcing, which varied from the central run comparable with the observed inter-annual variability in them. Seasonal sea level changes derived from the sensitivity experiments are shown in Fig. 21.

\subsection{Experiment 1: 50\% increase in river runoff}

Volga river runoff in 1982 was equal to $222.3 \mathrm{~km}^{3} / \mathrm{yr}$. According to the hydrometeorology service data for 1961-1997 period, at least in 4 years Volga river runoff was about to $50 \%$ higher, i.e. runoff value of $318 \mathrm{~km}^{3} / \mathrm{yr}$ has been observed in 1979 , as well as later in $1990\left(318 \mathrm{~km}^{3}\right), 1991\left(321 \mathrm{~km}^{3}\right)$, $1994\left(339 \mathrm{~km}^{3}\right)$. So in this experiment we look what will happen if we will increase the runoff of all rivers by $50 \%$. The reaction of the water budget and of sea level is quite expected and is almost linear. Mean sea level compared to the $\mathrm{CR}$ is increased by $28.3 \mathrm{~cm} / \mathrm{yr}$, corresponding to a value less than the $29.8 \mathrm{~cm} / \mathrm{yr}$ that would be obtained by linear extrapolation. The small non-linear response of the water budget is related to increased stability of the water column followed by an increase of SST, which leads to excessive evaporation compared to the $\mathrm{CR}$. The main consequence of increased runoff on circulation is the extension of western coastal current towards the south.

\subsection{Experiment 2: $50 \%$ increase in precipitation}

Based on linear extrapolation we expect an increase of $17 \mathrm{~cm} / \mathrm{yr}$ in sea level when precipitation is increased by $50 \%$ (Table 2), while the model gives an increase of $16.4 \mathrm{~cm} / \mathrm{yr}$. As in the first experiment, we have more stable water column especially in the SCB, due to excessive precipitation.

\subsection{Experiment 3: 50\% increase in wind speed}

Much stronger non-linear reaction occurs in the case of increased wind speed. Based on linear extrapolation, the sea level would be expected to drop by $43.2 \mathrm{~cm} / \mathrm{yr}$, amounting to $50 \%$ increase in annual evaporation (Table 2). Because mixing is enhanced by increased wind stress, both the sensible and latent heat fluxes are affected, thus considerably modifying the expected reaction. As cooling is increased, SST decreases by $1-2{ }^{\circ} \mathrm{C}$ compared to the CR, decreasing the surface humidity yielding a smaller specific humidity difference at the sea surface and at $10 \mathrm{~m}$ height $\left(q_{\text {surface }}-q_{10 \mathrm{~m}}\right)$. The increased wind stress also changes the circulation. The overall decrease of mean sea level produced by the model is $13.0 \mathrm{~cm} / \mathrm{yr}$, which is about 3.3 times smaller than expected from a proportional linear calculation.

\subsection{Experimant 4: $5^{\circ} \mathrm{C}$ warmer air temperature}

When air temperature is warmer and the dew point temperature is the same as that used in $\mathrm{CR}$, the obvious reaction of the model is an increase of SST (up to $2^{\circ} \mathrm{C}$ in summer) and corresponding increase of specific humidity at the sea surface, resulting in a more unstable atmospheric boundary layer with an increased Danton number $C_{E}$ by a factor of 1.2-1.3. More intensive evaporation, as a result of larger difference $C_{E}\left(q_{\text {surface }}-q_{10 \mathrm{~m}}\right)$, results in a sea level drop of $13.4 \mathrm{~cm} / \mathrm{yr}$ as compared to CR. 
Table 2. Water budget of the Caspian Sea. Water fluxes are given in $\mathrm{cm} / \mathrm{yr}$, expressed in units of mean sea level change.

\begin{tabular}{|c|c|c|c|c|c|c|}
\hline Period and source & $\begin{array}{r}\text { River } \\
\text { Runoff }\end{array}$ & $\begin{array}{r}\text { Underground } \\
\text { Inflow }\end{array}$ & Precipitation & Evaporation & $\begin{array}{r}\text { Outflow into } \\
\text { Kara-Bogaz-Gol }\end{array}$ & $\begin{array}{r}\text { Sea level } \\
\text { increment }\end{array}$ \\
\hline $\begin{array}{l}\text { 1970-1977 } \\
\text { (Bortnik and Nikonova, 1992) }\end{array}$ & 66.7 & 1.1 & 24.3 & -103.9 & 2.0 & -13.8 \\
\hline $\begin{array}{l}\text { 1978-1982 } \\
\text { (Baidin and Kosarev, 1986) }\end{array}$ & 85.8 & - & 25.7 & -97.9 & 0.7 & 14.0 \\
\hline $\begin{array}{l}\text { 1978-1990 } \\
\text { (Bortnik and Nikonova, 1992) }\end{array}$ & 81.9 & 1.1 & 23.0 & -91.8 & 0.5 & 13.7 \\
\hline 1982 (model) & 59.5 & 0 & 34.0 & -86.5 & 0 & 7.0 \\
\hline $\begin{array}{l}1982 \text { (ECMWF } \\
\text { data and observations) }\end{array}$ & $\begin{array}{r}59.5 \\
\text { (observed) }\end{array}$ & 0 & $\begin{array}{r}34.0 \\
(\mathrm{ECMWF})\end{array}$ & $\begin{array}{r}-95.7 \\
(\mathrm{ECMWF})\end{array}$ & 0 & -2.2 \\
\hline
\end{tabular}

\subsection{Experiment 5: warmer and more humid air}

An increase of the dew point temperature by $5^{\circ} \mathrm{C}$ compared to Experiment 4 affects the water balance in the opposite direction. Higher specific humidity of air prohibits the excessive evaporation observed in the previous experiment, leading to $6.2 \mathrm{~cm} / \mathrm{yr}$ higher rise of sea level compared to the CR and of $19.6 \mathrm{~cm} / \mathrm{yr}$ as compared to Experiment 4 . As a result of the restricted latent heat flux, the surface waters are warmer by $2{ }^{\circ} \mathrm{C}$ compared to Experiment 4 .

\subsection{Experiment 6: solar radiation without correction}

In the CR we have used ECMWF solar radiation heat flux with a correction factor of 1.05 to ensure better correspondence to climatologic estimates. The primary influence of correction of solar radiation is on the SST. In the experiment without correction we have $1^{\circ} \mathrm{C}$ lower SST compared to climatology, though the seasonal cycle of currents and of upper mixed layer show very little change. In response to the lower SST in the model we have lower evaporation, with an annual budget giving $5.7 \mathrm{~cm} / \mathrm{yr}$ higher rise of sea level as compared to $\mathrm{CR}$.

\subsection{Experiment 7: absorption of solar radiation at the sea surface}

In this experiment we have checked the sensitivity of the seasonal cycle of sea level to the parameterization of solar penetration into the sea. In Eq. (22) we put attenuation length for the short fraction of the solar radiation equal to $0.033 \mathrm{~m}$, such that all the solar radiation is absorbed in the first model layer. Compared to the CR, SST starts to increase much faster in the spring to produce a sharper thermocline and a shallower upper mixed layer. As a result, we have higher values of SST and of evaporation in the period from January till September. On the other hand, the balance between sensible and latent heat release from the sea is mod-

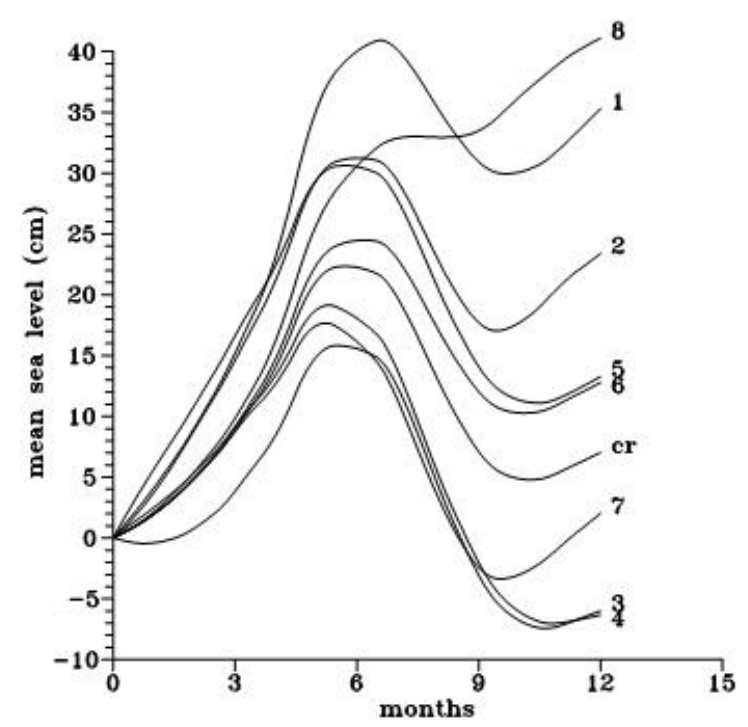

Fig. 21. Mean sea level seasonal cycle obtained from sensitivity experiments.

ified such that relatively larger part of the heat flux is accounted by sensible heat flux. In May, the sensible and latent heat fluxes are equal to $(-10.8 ;-65.2) \mathrm{W} / \mathrm{m}^{2}$ compared to $(-2.3 ;-43.5) \mathrm{W} / \mathrm{m}^{2}$ in the $\mathrm{CR}$, which means that the heat formerly released through evaporation or stored in the upper mixed layer is now released through sensible heat. In the period from September till December, the balance between sensible and latent heat fluxes is changed. In November we have $(-19.0 ;-73.6) \mathrm{W} / \mathrm{m}^{2}$ for sensible and latent heat fluxes as compared to $(-27.5 ;-90.2) \mathrm{W} / \mathrm{m}^{2}$ in the CR. The reduced penetration of heat into the sea results in stronger surface currents and more pronounced influence of baroclinicity on the circulation pattern. 


\subsection{Experiment 8: constant vertical mixing coefficients}

This experiment is designed to explore how the specification of mixing coefficients modifies the circulation. We take constant values of $K_{m}$ and $K_{h}$, equal to the maximum values of $(50 ., 10.) \times 10^{-4} \mathrm{~m}^{2} \mathrm{~s}^{-1}$ used in the CR. The reaction of the sea circulation is dramatic, sea currents become almost barotropic. The major effect of increased vertical mixing is a lowering of the SST by about $11^{\circ} \mathrm{C}$ in August and a corresponding decrease of evaporation from the sea surface as compared to the CR. Annual sea level rise is increased by $34.1 \mathrm{~cm} / \mathrm{yr}$ compared to the CR. The fall of sea level in August-October typical of the seasonal cycle in the CR is now absent, due to insufficient heat stored in the summer.

\section{Summary and conclusions}

A coupled sea hydrodynamics - air/sea interaction - sea ice thermodynamics model has been developed to simulate intra-annual variability of the Caspian Sea circulation and sea level. Complex bottom topography including large shallow areas, wide shelf and slope regions, interconnected subbasins, large freshwater inflows, sensitive response to atmospheric forcing, sea ice formation, and the observed level of climatic variability combined with man-made changes in hydrology make the Caspian Sea a challenging basin for testing and improving coupled models.

The model results and climatologic/observational data are analysed together to compare and discuss basic features of the simulated circulation and sea level change. The analyses reveal some fundamental features of the Caspian Sea circulation: summer upwelling along the eastern coast, west-east asymmetry in temperature which reverses between summer and winter in response to changes in upwelling and mixing dynamics, and an additional asymmetry in salinity resulting from fresh water influence. An important conclusion regarding circulation is the existence of cyclonic currents only in a depth averaged sense, considering the upper $50-100 \mathrm{~m}$. The earlier arguments for a cyclonic circulation in the MCB were partly based on the transport of warm water along the eastern shelf in winter. Our results show a persistent northward transport by subsurface currents along the eastern shelf slope, while the surface currents are more often directed southward. The analysis of observation made in the 1960's (Kosarev and Yablonskaya, 1994) and more recent times (Bondarenko, 1993) support the simulated current structure of the eastern shelf.

An important part of the work is the simulation of sea surface topography, yielding verifiable results in terms of sea level. Analyses of heat and water budgets confirm climatologic estimates of heat and moisture fluxes at the sea surface. Experiments performed with variations in external forcing suggest a sensitive response of the circulation and the water budget to atmospheric and river forcing, comparable with the inter-annual variability observed in these fields.

It is also shown that the model thermodynamics and the formulation of boundary conditions are not close to being perfect, although it is difficult to ascertain the sources of the discrepancies at this stage. For example, the correction of ECMWF derived solar radiation by a factor of 1.05 is justified partly by the corresponding climatologic estimate, and partly by closing the difference between simulated and climatologic fields of SST and sea level. It is of course quite possible that some drawbacks in model thermodynamics is hidden from the eye by this operative adjustment of solar radiation. Our aim for the future is to further improve model physics (better specifications of exchange coefficients, water import and export processes, and air-sea fluxes, especially in shallow regions), as well as improving the quality of external forcing (to include diurnal variation and better air-sea coupling), with particular emphasis on the simulation of deep water ventilation processes and upwelling dynamics, especially on the eastern coast.

Acknowledgements. The authors are grateful to NATO for support through the NATO SFP Programme, Project SFP-981063 providing us the means to carry out collaborative work. We thank A. Sarkisyan for useful discussions. We acknowledge the help of O. Gorelits from the State Oceanographic Institute, Moscow, who provided us with the Volga river runoff data. The research of R. A. Ibrayev was supported by Russian Foundation for Basic Research, grant \#08_05_01055-a.

Edited by: E. J. M. Delhez

\section{References}

Akhverdiev, I. O. and Demin, Y. L.: O structure sinopticheskih techeniy Kaspiiskogo morya $\mathrm{v}$ letniy sezon po rezultatam diagnosticheskih raschetov, in: Kaspiiskoe more. Struktura i dinamika vod, edited by: Kosarev, A. N., Nauka, Moscow, USSR, 5-15, 1989.

Arpe, K. and Roeckner, E.: Simulation of the hydrological cycle over Europe: Model validation and impacts of increasing greenhouse gases, Adv. Water Resour., 23, 105-119, 1999.

Badalov, A. B. and Rzheplinski, D. G.: Modelirovanie dinamiki deyatelnogo sloya Kaspiiskogo morya pod deystviem sinopticheskih atmosfernyh prosessov, in: Modelirovanie gidrofizicheskih prosessov i poley v zamknutyh vodoemah i moryah, Nauka, Moscow, edited by: Sarkisyan, A. S., USSR, 31-51, 1989.

Baidin, S. S. and Kosarev, A. N.: Kaspiiskoe more, Gidrologiya a Gidrohimiya, Nauka, Moscow, USSR, 1986.

Beron-Vera, F. J., Ochao, J., and Ripa, P.: A note on boundary conditions for salt and freshwater balances, Ocean Model., 1, 111118, 1999.

Bengtsson, L.: Climate modelling and prediction, Achievements and challenges, in: Proceedings of WMO/IOC/ICSU Conference On The WCRP Climate Variability And Predictability Study (CLIVAR), UNESCO, Paris, France, December 1998, 2-4, 1998. 
Betts, A. K., Ball, J. H., and Viterbo, P.: Basin-scale surface water and energy budgets for the Mississippi from the ECMWF reanalysis, J. Geophys. Res., 104(D16), 19293-19306, 1999.

Bondarenko, A. L.: Techeniya Kaspiiskogo morya i formirovanie polya solenosti vod Severnogo Kaspiya, Nauka, Moscow, Russia, 1993.

Bortnik, V. N. and Nikonova, R. E.: Vodnyi balans, in: Terziev, Gidrometeorologiya i Gidrohimiya Morey, Vol.6: Kaspiiskoe more, Iss.1: Gidrometeorologicheskie usloviya, edited by: Kosarev, F. S. and Kerimov A. A., Hydrometeoizdat, St. Petersburg, Russia, 211-221, 1992.

Csanady, G. T.: Circulation in the Coastal Ocean, D. Reidel Publ. C., 1982.

Esbensen, S. K. and Reynolds, R. W.: Estimating monthly averaged air-sea transfers of heat and momentum using bulk aerodynamic method, J. Phys. Ocean., 11, 457-465, 1981.

Ibrayev, R. A., Sarkisyan, A. S., and Trukhchev, D. I.: Seasonal variability of the circulation of the Caspian Sea reconstructed from mean multi-year hydrological data, Izvestiya, Atmos. Ocean. Phys., 37(1), 103-111, 2001.

Ibrayev, R. A.: Model of enclosed and semi-enclosed sea hydrodynamics, Russ. J. Numer. Anal. M., 16(4), 291-304, 2001.

Kamenkovich, V. M.: Osnovy dinamiki okeana, Hydrometeoizdat, Leningrad, USSR, 1973.

Kosarev, A. N.: Gidrologiya Kaspiiskogo i Aralskogo morey, Moscow University Press, Moscow, USSR, 1975.

Kosarev, A. N. and Tuzhilkin, V. S.: Klimaticheskie termohalinnye polya Kaspiiskogo moray, Moscow University Press, Moscow, Russia, 1995.

Kosarev, A. N. and Yablonskaya, E. A.: The Caspian Sea, SPB Academic Publishing, 1994.

Launiainen, J. and Vihma, T.: Derivation of turbulent surface fluxes - an iterative flux-profile method allowing arbitrary observing heights, Environ. Softw., 5(3), 113-124, 1990.

Lednev, V. A.: Techeniya Severnogo i Srednego Kaspiya, Morskoy Transport, Moscow, USSR, 1943.

Martin, P. J.: Simulation of the mixed layer at OWS November and Papa with several models, J. Geophys. Res., 90(C0), 903-916, 1985.

Munk, W. H. and Anderson, E. R.: Note on the theory of the thermocline, J. Mar. Res., 7, 276-295, 1948.

Panin, G. N.: Isparenie i teploobmen Kaspiiskogo moray, Nauka, Moscow, USSR, 1987.

Paulson, E. A. and Simpson, J. J.: Irradiance measurements in the upper ocean, J. Phys. Oceanogr., 7, 952-956, 1977.
Rodionov, S. N.: Global and regional climate interaction: The Caspian Sea experience, Ser. Water and Technology Library, Kluwer Academic Publishers, 11, 1994.

Roulett, G. and Madec, G.: Salt conservation, free surface, and varying levels: a new formulation for ocean general circulation models, J. Geophys. Res., 105(C10), 23927-23942, 2000.

Samoilenko, V. S. and Sachkova, A. I.: Kompleksnye gidrometeorologicheskie atlasy Kaspiiskogo I Aralskogo morey, Hydrometeoizdat, Leningrad, USSR, 1963.

Sarkisyan, A. S., Zaripov, B. R., Kosarev, A. N., and Rzheplinski, D. G.: Diagnosticheskie raschety techeniy v Kaspiiskom more, Izvestiya AN, Fizika Atmos. i Okeana, 12(10), 1106-1110, 1976.

Schrum, C. and Backhaus, J. O.: Sensitivity of atmosphere-ocean heat exchange and heat content in North Sea and Baltic Sea, A comparitive Assessment, Tellus, 51A, 526-549, 1999.

Schrum, C., Staneva, J., Stanev, E., and Ozsoy, E.: Air-sea exchange in the Black Sea estimated from atmospheric analysis for the period 1979-1993, J. Mar. Syst., 31, 3-19, 2001.

Stockman, W.: Issledovaniya kinematiki techeniy u zapadnogo berega $\mathrm{v}$ sredney chasti Kaspiiskogo moray, Transactions of the Azerbaidjan Scientific-Investigative Fishery station, Baku, USSR, 1, p. 76, 1938.

Sur, H. I., Ozsoy, E., and Ibrayev, R.: Satellite - Derived Flow Characteristcs of the Caspian Sea, in: Satellites, Oceanography and Society, edited by: Halpern, D., Elsevier Science B. V., 289297, 1998.

Terziev, F. S., Kosarev, A. N., and Kerimov, A. A.: Gidrometeorologiya i Gidrohimiya Morey, Kaspiiskoe more, Gidrometeorologicheskie usloviya, Hydrometeoizdat, St. Petersburg, Russia, 6, 1, 1992.

Timofeev, N. A.: Radiacionnyi regim okeanov, Naukova Dumka, Kiev, USSR, 1983.

Trukhchev, D., Kosarev, A., Ivanova, D. and Tuzhilkin, V.: Numerical analysis of the general circulation in the Caspian Sea, Comptes Rendus de l'Academie Bulgare des Sciences, Sofia, 48(10), 35-38, 1995.

Tuzhilkin, V. S., Kosarev, A. N., Trukhchev, D. I., and Ivanova, D. P.: Sezonnye osobennosti obchey cirkulyacii vod glubokovodnoy chasti Kaspiiskogo moray, Meteorologiya I Gidrologiya, 1, 9199, 1997.

UNESCO: Seventh Report of the Joint Panel on Oceanographic Tables and Standards, UNESCO Techn. Papers, Mar. Sci., 24(1), 39-54, 1976. 